\title{
Assessment of an extended version of the Jenkinson-Collison classification on CMIP5 models over Europe
}

\author{
Noelia Otero $^{1}$ (D) Jana Sillmann $^{2} \cdot$ Tim Butler $^{1}$
}

Received: 1 December 2016 / Accepted: 21 April 2017 / Published online: 26 April 2017

(c) The Author(s) 2017. This article is an open access publication

\begin{abstract}
A gridded, geographically extended weather type classification has been developed based on the Jenkinson-Collison (JC) classification system and used to evaluate the representation of weather types over Europe in a suite of climate model simulations. To this aim, a set of models participating in the Coupled Model Intercomparison Project Phase 5 (CMIP5) is compared with the circulation from two reanalysis products. Furthermore, we examine seasonal changes between simulated frequencies of weather types at present and future climate conditions. The models are in reasonably good agreement with the reanalyses, but some discrepancies occur in cyclonic days being overestimated over North, and underestimated over South Europe, while anticyclonic situations were overestimated over South, and underestimated over North Europe. Low flow conditions were generally underestimated, especially in summer over South Europe, and Westerly conditions were generally overestimated. The projected frequencies of weather types in the late twenty-first century suggest an increase of Anticyclonic days over South Europe in all seasons except summer, while Westerly days increase over North and Central Europe, particularly in winter. We find significant changes in the frequency of Low flow conditions and the Easterly type that become more frequent during
\end{abstract}

Electronic supplementary material The online version of this article (doi:10.1007/s00382-017-3705-y) contains supplementary material, which is available to authorized users.

Noelia Otero

Noelia.OteroFelipe@iass-potsdam.de

1 Institute for Advanced Sustainability Studies eV., Potsdam, Germany

2 CICERO Center for International Climate Research, Oslo, Norway the warmer seasons over Southeast and Southwest Europe, respectively. Our results indicate that in winter the Westerly type has significant impacts on positive anomalies of maximum and minimum temperature over most of Europe. Except in winter, the warmer temperatures are linked to Easterlies, Anticyclonic and Low Flow conditions, especially over the Mediterranean area. Furthermore, we show that changes in the frequency of weather types represent a minor contribution of the total change of European temperatures, which would be mainly driven by changes in the temperature anomalies associated with the weather types themselves.

\section{Introduction}

Analysis of large-scale atmospheric circulation by means of synoptic weather-typing has been widely studied over the last few decades. There is an increasing interest in developing atmospheric classifications, given that they are considered as useful tools for a better understanding of the relationship with surface climate. Synoptic classifications aim to simplify the continuum of atmospheric circulation into a reduced number of representative categories (Huth et al. 2016). Therefore, atmospheric variability can be analysed in terms of changes of frequencies of specific synoptic weather types (WT) (Huth 2000). Numerous WT classifications have been used for a wide range of applications: human mortality (Kassomenos et al. 2001); surface climate variables, such as precipitation (Goodess and Jones 2002; Trigo and DaCamara 2000; Lorenzo et al. 2008; Cortesi et al. 2013) or temperature (Chen 2000; Post et al. 2002); extreme events, such as storms (Donat et al. 2010a), or droughts (Paredes et al. 2006; Vicente-Serrano and LópezMoreno 2006); environmental variables, such as wildfire 
occurrence (Kassomenos 2010) or air quality (Comrie 1992; Kallos et al. 1993; Tang et al. 2011; Demuzere et al. 2009a; Russo et al. 2014). A comprehensive discussion of the different methods and their applicability can be found in Huth et al. 2016 and the references therein.

Most of the WT classification systems have been developed in specific regions around the world, especially in mid-latitudes where synoptic variability is an important driver of regional weather conditions (Huth et al. 2008). Such classifications have covered almost all of Europe (Huth et al. 2016), and there have also been many studies describing synoptic situations over the world: North America (Sheridan 2002; Lee 2015), Australia (Hart et al. 2006), New Zealand (Jiang 2010), or Asia (Chen et al. 2008).

The present study aims to investigate the applicability of a gridded WT classification, based on the traditional Lamb WT (1972), which was objectively implemented by Jenkinson and Collison (1977) (hereinafter JC). This classification, originally developed for the British Isles, has been one of the most prominent WT classification schemes applied in mid-high latitudes. An extensive number of studies that use the JC procedure can been found in the literature and they have mainly focused on Europe: Trigo and DaCamara (2000), Linderson (2001), Goodess and Jones (2002), Spellman (2000), Chen (2000), Grimalt et al. (2012), Lorenzo et al. (2008), Post et al. (2002), Buishand and Brandsma (1997), Cortesi et al. (2013), among others. Besides these areas, this scheme has been applied in other regions where it has been rarely used so far, such as USA (Wilby et al. 1995), China (Liwei et al. 2006), Taiwan (Lai 2010), Chile (Espinoza et al. 2014), the Arabian Peninsula (El Kenawy et al. 2014), or Russia (Spellman 2015). Given the numerous existing studies in which the JC classification has been applied, we aim to contribute with a geographically extended implementation of the original scheme. One of the main advantages of our approach is that synoptic atmospheric conditions can be assessed at every grid-point over the map (or over a particular region). One representative example of its application in terms of air pollution can be found in Otero et al. (2016).

Atmospheric classifications are also applicable to general circulation model (GCM) outputs, which would allow evaluation of model performance and examination of changes in atmospheric circulation (Huth 2000; Lorenzo et al. 2011). Since GCMs are considered a state-ofthe-art tool in climate change analyses, it is important to investigate whether they are able to reproduce realistic patterns of atmospheric circulation. Moreover, it is known that GCMs are better at simulating the general circulation than some surface variables (e.g., precipitation) (Yarnal et al. 2001). Different approaches have been used to evaluate the accuracy of the atmospheric circulation simulated by the GCMs. Demuzere et al. (2009b) studied the present and future ECHAM5 sea level pressure using Lamb WT in Belgium, and they found some discrepancies between simulated and observed WT, which might be due to seasonal mean bias. Similarly, Lorenzo et al. (2011) assessed future changes in the frequency of synoptic WT over the northwest Iberian Peninsula in the twenty-first century using a small set of GCMs. Pérez et al. (2014) showed the different performance for reproducing synoptic patterns in a larger set of GCMs as part of the Coupled Model Intercomparison Project phase 3 (CMIP3, Meehl et al. 2007) and phase 5 (CMIP5, Taylor et al. 2012), respectively. El Kenawy and McCabe (2016) assessed the capability of a set of CMIP5 models to reproduce synoptic conditions over the Arabian Peninsula, and they suggested that models with higher spatial resolution tend to perform better than those models with coarser resolution. In this context, several authors suggest that the model performance for reproducing circulation types might dependent on the study region as well as the selected variable, and they show that some models give more realistic results, but there is no single one GCM better than others (Belleflamme et al. 2013; Casado and Pastor 2012).

Given the strong relationship between synoptic patterns and local climate variables, atmospheric circulation is often described as one key driver of variability of most surface meteorological parameters, such as air temperature (Post et al. 2002; Riediger and Gratzkil 2014) and extreme temperature events (Della-Marta et al. 2007). Cahynová and Huth (2016) assessed the influence of changes in circulation WT on seasonal trends in temperature as well as precipitation at several European stations, finding a strong link in winter. Another representative study for the Iberian Peninsula confirmed that atmospheric circulation patterns could provide valuable information to examine spatial and temporal variations of maximum and minimum temperature (Peña-Angulo et al. 2016). Future projections have suggested a temperature increase over the next decades over Europe (Meehl et al. 2007) with a higher probability of heatwaves according to regional climate projections (Russo et al. 2015). Circulation changes could either mitigate or enhance changes in surface variables, such as surface temperature or precipitation (Belleflamme et al. 2015). Moreover, it has been shown that this relationship between WT and local meteorological conditions has important implications for future air quality given the strong link between climate and air pollution (Jacob and Winner 2009). Hence, it is important to analyse whether changes in European temperatures are due to changes in the frequencies of WTs or due to within-types variations, which are changes that cannot be explained by changed WT frequencies, but would be assigned to changes in the characteristics of the patterns themselves (Barry and Perry 1973; Beck et al. 2007). 
Taking all of this into account, this paper has two main purposes. First, we present a new implementation of the objective JC classification by applying a movable 16-point mask to every grid point in climate model output. In particular, the present study analyses its utility in the European region. Second, we aim to evaluate the quality of GCMs to reproduce atmospheric circulation by means of weather types. To do this, a set of state-of-the-art global models is selected from the CMIP5 ensemble, and they are compared to two different reanalyses. Furthermore, we use future simulations from these models to investigate projected changes in atmospheric circulation. Finally, we examine the influence of WT frequency on maximum and minimum temperature in the present and coming decades.

The paper is organised as follows: Sect. 2 presents the different datasets (i.e., reanalyses and GCMs output). Section 3 describes the implementation of the procedure, the methods to evaluate the capability of models in reproducing realistic patterns, and the methodology to examine the influence of WT on European maximum and minimum temperatures. Section 4 discusses the results, and the summary and final remarks are in Sect. 5.

\section{Data}

\subsection{Reanalyses}

Reanalyses can be considered as the most reliable data sets for comparison with global model output (Pérez et al. 2014). In this study, we use two variables, mean sea level pressure (MSLP) and near surface temperature, extracted from two different reanalyses. ERA-Interim is the latest global atmospheric reanalysis produced by the European
Centre for Medium-Range Weather Forecasts (ECMWF) from 1979 to present (Dee et al. 2011). National Center for Environmental Prediction/National Center for Atmospheric Research (NCEP/NCAR) provides the NCEP-DOE Reanalysis II (NCEP2), an improved version of the NCEP-NCAR Reanalysis I. The NCEP2 covers the "20-year" satellite period of 1979 to the present and uses an updated forecast model, updated data assimilation system, improved diagnostic outputs, and fixes for the known processing problems of the NCEP-NCAR reanalysis (Kanamitsu et al. 2002).

For classifying weather types, the 6-hourly mean sea level pressure are averaged over a 24-hourly period to obtain daily values during the period 1986-2005. Daily maximum and minimum temperatures provide the basic information to make inferences about changes in longreturn period extreme events (Zhang et al. 2011). Thus, daily maximum and minimum temperatures were approximated by daily maximum and minimum of the 6-hourly of the $2 \mathrm{~m}$-temperature values, respectively. The ERA-Interim data were available at $1^{\circ} \times 1^{\circ}$ regular (latitude/longitude) resolution, while the $2.5^{\circ} \times 2.5^{\circ}$ MSLP from NCEP2 was interpolated to a finer $1^{\circ} \times 1^{\circ}$ grid. Correspondingly, 2 m-temperature from NCEP2 has been also interpolated to the same grid from a global T62 Gaussian grid $(192 \times 94)$. For our analysis, 20 years (1986-2005) of each reanalysis dataset were selected, which are considered as the reference period in this study.

\subsection{CMIP5 global climate models}

In order to assess how models are able to reproduce realistic patterns of WT across Europe as well as their influence on maximum and minimum temperature, we use a set of state-of-the-art coupled GCMs participating in CMIP5

Table 1 CMIP5 models included in this study: names of models, institutions, resolution and the variables used for each experiment (piControl, historical and RCP8.5)

\begin{tabular}{llllll}
\hline Model name & Modeling Center & lon-lat & piControl & Historical & RCP8.5 \\
\hline BNU-ESM & Beijing Normal University, China & $2.8^{\circ} \times 2.8^{\circ}$ & $1871-1970$ & slp & slp,tasmax,tasmin slp,tasmax,tasmin \\
CCSM4 & National Center for Atmospheric Research, USA & $0.94^{\circ} \times 1.25^{\circ}$ & $1001-1100$ & slp & slp,tasmax,tasmin slp,tasmax,tasmin \\
CESM1 (CAM5) & National Science Foundation, Department of & $0.94^{\circ} \times 1.25^{\circ}-$ & - & slp,tasmax,tasmin slp,tasmax,tasmin \\
& $\quad$ Energy, National Center for Atmospheric Research & & & & \\
CanESM2 & Canadian Center for Climate Modeling and Analy- & $2.8^{\circ} \times 2.8^{\circ}$ & $2016-2115$ & slp & slp,tasmax,tasmin slp,tasmax,tasmin \\
& $\quad$ sis, Canada & $1.12^{\circ} \times 1.12^{\circ}-$ & - & slp,tasmax,tasmin slp,tasmax,tasmin \\
EC-EARTH & EC-EARTH consortium & $2.5^{\circ} \times 2.0^{\circ}$ & - & - & slp,tasmax,tasmin slp,tasmax,tasmin \\
GISS-E2-R & NOAA Geophysical Fluid Dynamics Laboratory & $3.75^{\circ} \times 1.9^{\circ}$ & $1900-1999$ & slp & slp,tasmax,tasmin slp,tasmax,tasmin \\
IPSL-CM5A-LR & Institut Pierre-Simon Laplace, France & $2.8^{\circ} \times 2.8^{\circ}$ & $1900-1999$ & slp & slp,tasmax,tasmin slp,tasmax,tasmin \\
MIROC-ESM & Model for Interdisciplinary Research on Climate, & & & &
\end{tabular}

The column for the piControl experiment also details the period of 100 years used for each model 
(Taylor et al. 2012) (Table 1). In particular, this study uses daily sea level pressure, and maximum and minimum temperature values. Three sets of experiments have been used, namely, preindustrial control model runs (piControl), historical experiments for analysing past and present climate conditions and a future scenario, RCP8.5, which assumes high rates of greenhouse gas emissions by 2100 (Moss et al. 2010).

The preindustrial control experiment serves as the baseline for analysis of historical and future scenario runs with prescribed concentrations of well-mixed GHGs (Taylor et al. 2012). In this study, piControl model runs have been included to quantify changes in the frequency of weather types due to the natural variability. In such case, a longer period of 100 years was taken from a smaller set of seven models that were available (Table 1), while 20 years is the period of analysis considered for historical (1986-2005) and RCP8.5 (2081-2100) experiments. It is worth mentioning that one single integration, in particular ensemble member 1 , was taken from each of the models, with the only exception of the GISS-E2-R model, for which ensemble member 1 was not available, and thus member 6 was chosen. Previous work pointed out that results from different ensemble members of GCMs are quite similar for atmospheric circulation (Belleflamme et al. 2013). Hence, we do not expect significant changes in our conclusions if several ensemble members were considered. Moreover, the use of only one member for each model gives equal weight to all models (Barnes and Polvani 2015). The GCM fields considered here have also been interpolated to a regular grid of $1^{\circ}$ latitude by $1^{\circ}$ longitude, consistent with the reanalyses' resolution used here.

\section{Methods}

\subsection{Classification of WT: a gridded JC-implementation}

The automated Lamb WT classification was performed by Jenkinson and Collison (1977) and refined by Jones et al. (1993). The original catalogue was defined for the British Isles, using a coarsely gridded daily MSLP on a 16 point grid (p1-p16) with a $10^{\circ}$ resolution in zonal and a $5^{\circ}$ resolution in meridional directions, for a central point located at $55^{\circ} \mathrm{N}$ latitude and $5^{\circ} \mathrm{W}$ longitude (Jenkinson and Collison 1977). With this scheme, the circulation pattern for a given day is described using the location of the center of high and low pressure that determine the direction of the geostrophic airflow. The only input that the JC classification requires is MSLP, which is one of the main advantages, since free atmospheric variables are considered reasonably well simulated by GCMs (Goodess and Palutikof 1998). The principle for identifying synoptic patterns is based on the analysis of the strength and direction of the airflow and the type of the baric system (cyclonic or anticyclonic).

The choice of this classification was mainly motivated by its simplicity in terms of the input data (MSLP), the relatively easy interpretation of the underlying airflow indices for the resulting weather types and because its definition allows transferability to other regions with a simple implementation. Although this method does not consider the temporal evolution of weather situations and the flow analysis is based on the specific central point of the area defined for the 16 points, in theory it can be applied anywhere over mid-latitudes (Donat et al. 2010a). Therefore, we developed a gridded JC classification taking each grid-point over the map as the central point surrounded by the 16 points that would describe the synoptic situation for the given central point. We applied this implementation globally with exception of the poles, and the tropical areas between $0-15^{\circ} \mathrm{N}$ and $0-15^{\circ} \mathrm{S}$. The analyses presented in the following will focus only on the European region $\left(13^{\circ} \mathrm{W}-34^{\circ} \mathrm{E}, 34-71^{\circ} \mathrm{N}\right)$ by using a total of 1824 central points. According to the scheme, daily circulation is characterized through the use of a set of six indices associated to the direction and vorticity of geostrophic flow: meridional or southerly flow (SF), zonal or westerly flow (WF), total flow (F), southerly shear vorticity (ZS), westerly shear vorticity (ZW) and total shear vorticity $(Z)$. The westerly and southerly flow components describe the zonal and meridional flow over the area, while total shear vorticity provides information about the rotation of the atmosphere (Jones et al. 1993). The comparison between the total flow and the total vorticity sets the rules for defining the WT (see the Appendix). Initially, 27 WTs are obtained: eight directional types, two types that describe atmospheric rotation, 16 hybrid-combined types and one "Unclassified" type representing weak or chaotic flow. According to the original scheme, the hybrid types count equally as a

Table 2 Acronym of the 27 total types obtained after applying the rules of the JC classification

\begin{tabular}{lllll}
\hline Vorticity & Directional & Hybrid & & Low flow \\
\hline $\mathbf{A}$ & $\mathbf{N}$ & AN & CN & LF \\
$\mathbf{C}$ & $\mathbf{N E}$ & ANE & CNE & \\
& $\mathbf{E}$ & AE & CE & \\
& SE & ASE & CSE & \\
& S & AS & CS & \\
& SW & ASW & CSW & \\
& $\mathbf{W}$ & AW & CW & \\
& $\mathbf{N}$ & ANW & CNW & \\
\hline
\end{tabular}

A final set of 11 types is finally retained (bold letters) 
half occurrence to each of their major types (pure directional and cyclonic/anticyclonic). Thus, only $11 \mathrm{WTs}$ are retained, according to their directional characteristics (Table 2). Further details about the procedure for classifying the types can be found in Jones et al. 1993.

The JC classification has been applied to different grid resolution, $5^{\circ} \times 5^{\circ}$ (Trigo and DaCamara 2000), and other configurations of points (Dessouky and Jenkinson 1977; Spellman 2000; Grimalt et al. 2012). According to the original catalogue, Unclassified days are reallocated with a threshold for total flow and vorticity, which might be readjusted for a specific region (Goodess and Palutikof 1998; Conway et al. 1996). For instance, Post et al. (2002) adapted the scheme for higher isobaric levels, using the standard deviations of F and Z, while Lai (2010) defined the threshold testing several appropriated values for the particular area of study. A sensitivity test of Unclassified days on grid sizes and resolutions was performed in Demuzere et al. (2009b), concluding that the number of these days would decrease with grid resolution. Other authors did not consider the Unclassified type due to the few cases in the particular study area and they decided to regroup Unclassified days among the retained classes (Trigo and DaCamara 2000; Cortesi et al. 2013; El Kenawy et al. 2014). Previous studies found a significant increase of portion of Unclassified days in summer and autumn when applying JC classification. Particularly, in the Iberian Peninsula this was attributed to the low-pressure gradient that characterises this area during those seasons (Goodess 2000; Grimalt et al. 2012).

Here, we adopted the same original JC classification and the 11 types described in Jones et al. 1993. For our purposes, the presence of Unclassified days also provides valuable information with regard to the atmospheric state characterized by weak flow. Therefore, our gridded version of the JC classification uses a static threshold (detailed in the Appendix) for every grid-point allowing for Unclassified days, which in the following we refer to as Low Flow (LF) type.

\subsection{Model evaluation}

In order to evaluate the skill of the GCMs, we assess whether models are able to reproduce realistic frequencies of WT when compared with reanalysis data. The model performance is evaluated according to their ability to reproduce seasonal relative frequencies of WT averaged over the reference period (1986-2005). We focus on examining seasonal variations in the accuracy of model simulations, where December, January and February are taken as winter (DJF), March, April and May as spring (MAM), June, July and August as summer (JJA), and September, October and November as autumn (SON). We examine seasonally spatial differences between the frequencies obtained from reanalyses and models for each WT at every grid-point, applying the common Student's t-test in order to analyse where those differences are statistically significant. The use of multi-model ensemble simulations is recommended since they have been shown to outperform individual models, and they are also expected to provide good estimates of future changes (Sillmann et al. 2013; Weigel et al. 2007). Therefore, we also include the multi-model ensemble (MME) mean of the frequencies of the individual models for each weather type.

The performance of GCMs is assessed through the spatial correlations between reanalysis and models' frequencies of WT derived from the seasonal average over 20 years. In this sense, we assess the spatial distribution, rather than temporal correspondence by using the Taylor diagram technique (Taylor 2001). A Taylor diagram is a graphic method to summarise how closely models match a reference dataset (e.g., reanalysis), and it is quantified in terms of the correlation $(\mathrm{R})$, the centered rootmean-squareerror (RMSE) and the amplitude of their variations, represented by their standard deviations (Std) (Taylor 2001). Thus, correlations between the WT frequencies simulated by models and those from the reanalysis, as well as standard deviations are depicted in the same diagram providing a comprehensive picture about the skill of the models in reproducing seasonal frequencies of WT. The statistics are normalised, dividing both the RMSE and the Std of the models by the Std obtained from the reanalyses in order to display the ability of the models for all seasons in the same plot for each WT.

Moreover, an objective index is used to assess the ability of models to reproduce the overall occurrence of WT. The Scatter Index (SI) measures the differences between the frequencies of all WT from the reanalyses and those from the models, and is defined as the root mean square error normalized by the mean frequency (Pérez et al. 2014). Here, we examine the spatial skill of each model computing a SI from seasonal relative frequencies during the reference period for the 11 WT types following the approach described in Pérez et al. 2014:

$S I=\sqrt{\frac{\sum_{i=1}^{N}\left(p_{i}-p_{i}^{\prime}\right)^{2}}{N}} / \frac{\sum_{i=1}^{N} p_{i}}{N}$

where $p_{i}$ is the relative observed frequency (here, the reanalysis frequency) of the $i$ th type for the reference period, and $p_{i}^{\prime}$ is the relative simulated frequency, and $\mathrm{N}$ is the number of WT (11 in our case). Lower values of SI indicate better agreement between reanalysis and model data and hence a better performing GCM (Pérez et al. 2014).

Future changes in atmospheric large-scale circulation are assessed in terms of changes in the frequencies of WT. 
For the late twenty-first century, we examine the WT for the period 2081-2100 for each model. Then, we compare relative frequencies of simulated patterns for this period for each model and the corresponding frequencies for each model during the reference period (1986-2005). A Student's t-test at the 5\% confidence level is applied to assess the significance of the frequency changes. Here, we also follow the strategy of computing a multi-model ensemble (MME) by averaging over all models.

\subsection{Temperature patterns derived from WT}

Large-scale circulation and local processes may induce extreme episodes (e.g., heatwaves or cold spells), which are generally derived from unusual synoptic conditions (Cattiaux et al. 2010). In order to get more insight into the physical conditions behind the link between weather types and temperature, we examine seasonal composite temperature maps for each WT. Composite maps derived from anomalies of daily maximum and minimum temperature (Tmax and Tmin, respectively) into each WT are used to assess the impact of WT on temperatures. The seasonal anomalies are computed from the whole period of time. First, we analyse the distribution of temperature anomalies for each WT for the reanalyses at the reference period, and then we examine the models responses for the same time period. Links between WT and projected temperatures are also assessed through composites of seasonal temperatures anomalies. A common Student's t-test is applied in order to determine the areas where the mean of anomalies is statistically significant different from zero.

As previous studies pointed out, weather types can be sensitive to future climate forcing (Wilby et al. 2004). As a result, a warmer climate might influence the occurrence of WT as well as their relationship with regional climate (Boé et al. 2006). It is important to assess the role that changes in the WT frequency might play on future temperatures. In order to quantify the changes in future temperatures due to changes in the frequencies of circulation patterns, we use a simple decomposition of climatic difference between each period into: (1) changes in temperature anomalies caused by changes in the frequency of WT (frequency-related changes); and (2) changes in the temperature anomalies within each WT (within-type changes). This approach originally proposed by Barry and Perry (1973) has been used to decompose the monthly changes in Central Europe (Beck et al. 2007), climatic trends (Cahynova and Huth 2016), or multi-decadal changes of temperature and precipitation in Europe (Küttel et al. 2011). Here, we use this method to assess potential changes in future temperatures due to the changes in the frequency of weather types. The total change of temperature $(\Delta \bar{C})$ between the future and the reference period can be expressed as follows:
$\Delta \bar{C}=\sum_{i=1}^{G} \Delta F_{i}\left(C_{i}+\Delta C_{i}\right) / n+F_{i} \Delta C_{i} / n$

where $\mathrm{G}$ is the number of WT (11), $F_{i}$ is the frequency of type $i$ during the reference period, $\Delta F_{i}$ is the change of the frequency of type $i$ between reference and future period, $C_{i}$ is the climatic mean of type $i$ at the reference period, $\Delta C_{i}$ is the change of climate means for $i$ type between both periods, and $\mathrm{n}$ is the number of time units (days) during the first period.

The first term in Eq. (2) represents the change of temperature between both periods (future and reference) that can be attributed to frequency changes of WT (i.e., frequency-related changes). The second term describes the change that can be assigned to the changes of the characteristics of the patterns, but also due to the modification of the link between the weather types and regional climate (i.e., within-type changes). Following this approach, we assess the influence of the changes of WT frequencies on future average daily maximum and minimum temperature.

\section{Results}

\subsection{Evaluation of model performance in simulating WT}

In order to examine how closely models reproduce circulation patterns compared to reanalyses, we examine relative frequencies over the entire European domain during the reference period (1986-2005). Here, one must acknowledge the potential caveat in using a relatively short period of time (i.e., 20 years) that may affect climate estimates due to multi-decadal variability inherent in the models (Donat et al. 2010b). We compare averaged frequencies from reanalyses, ERA-Interim and NCEP2, and a MME computed from the historical CMIP5 runs. Moreover, to get insight about changes in synoptic patterns due to the natural variability, we also include multi-model averaged frequencies of each weather type over Europe computed from the 100year piControl runs (Table 1).

Figure 1 depicts seasonal relative frequencies for each weather type. Overall, models are able to reproduce the seasonal frequencies of WT, and there is a reasonable agreement between reanalyses and the MME. The frequency distribution averaged over the whole domain for reanalyses and the MME shows that Anticyclonic (A) is the most frequent type, followed by Cyclonic (C), Westerly (W) and Low Flow (LF). The least frequent type is flow from the easterly sector (NE, E, SE). In autumn and winter, apart from $\mathrm{A}$ and $\mathrm{C}$, there is a large proportion of the three types 


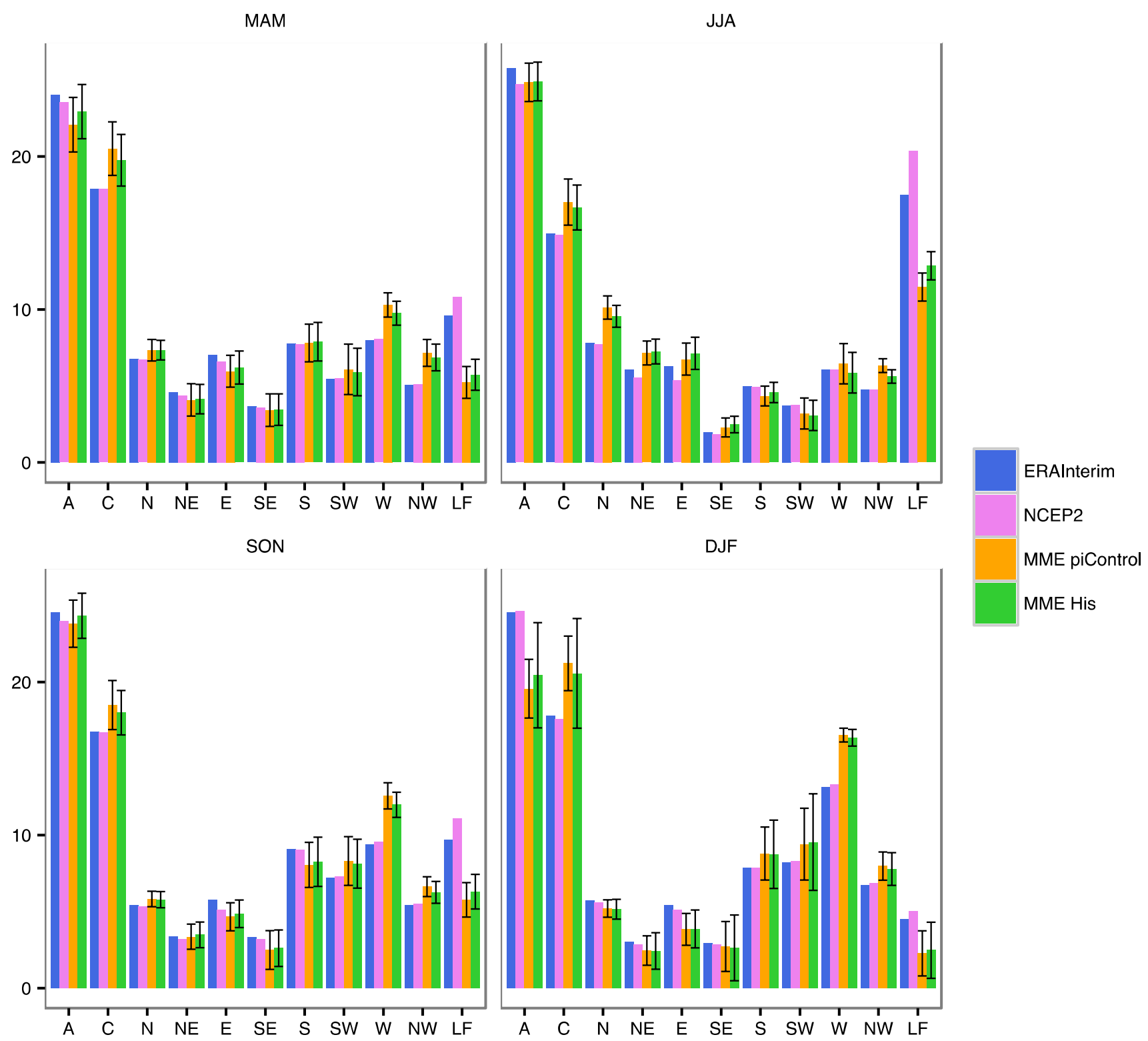

Fig. 1 Relative seasonal frequencies (\%) of each weather type averaged over the European domain at the reference period 1986-2005 for the reanalysis, ERA-Interim and NCEP2, and also for the multimodel ensemble (MME His) from the set of the ten models of historical runs. Another multi-model ensemble from pre-industrial runs is provided (MME piControl) from a smaller set of seven models computed over 100 years. Uncertainty bars show the standard deviations for both multi-model ensemble (MME piControl and MME His) calculated over the time period with the westerly component, namely Westerly (W), Southwesterly (SW) and Northwesterly (NW). In spring and summer, the Easterly (E) and North-easterly (NE) types appear to be more frequent as well as the Northerly $(\mathrm{N})$. On the contrary, the occurrence of Southerly (S) situations is less frequent in spring and summer. The LF conditions become more frequent in summer, although in autumn and spring there is also an enhanced frequency of LF days.

Both MMEs, i.e., from the piControl and historical simulations, show most of these features, but some discrepancies can be noticed for some specific WT. The most significant difference is found for the type LF in all seasons, but specifically in summer. Models generally underestimate the number of LF days. The discrepancies are also evident when comparing both reanalyses due to the larger contribution of LF days shown by NCEP2. The MME of piControl does not show important differences compared to the MME from historical runs. Standard deviations, calculated over years during the study period for both MMEs, quantify the variability over time of each WT. 
There are no substantial differences when comparing the spread among the WT in the piControl and the historical runs. We found larger uncertainty relative to frequency for most of the WT in winter, specifically for the easterlies and the LF types.

The ability of the models to reproduce the spatial patterns of relative WT frequencies over Europe is assessed by direct comparison with the corresponding WT for reanalysis data during the reference period. Although both reanalyses, ERA-Interim and NCEP2, have been considered for the analysis of model performance, the next sections only include results obtained for ERA-Interim due to the close similarities between the two. The supplementary material contains the main results of the comparison of MMEs with NCEP2.

In order to compare the WT frequencies from the ERAInterim and those simulated by the models over Europe, we use the MME computed from the CMIP5 models in the reference period. Figure 2 illustrates the biases between seasonal frequencies of WT from the MME and ERA-Interim during the reference period for the most frequent types (i.e., A, C, W and LF). Overall, the differences between the frequencies of those WTs were found to be statistically significant over South and North Europe. Despite the models
MAM

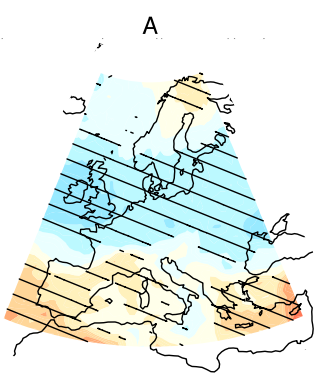

MAM

C

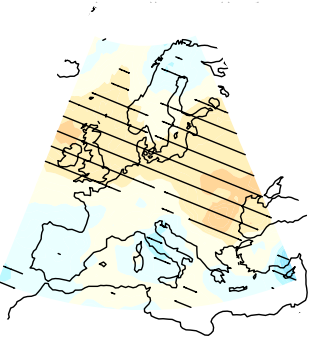

MAM
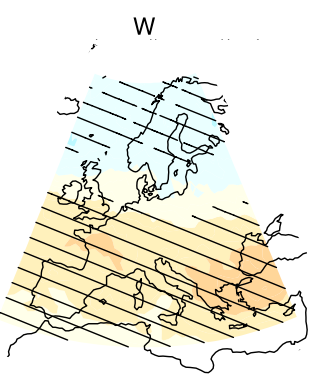

MAM

LF

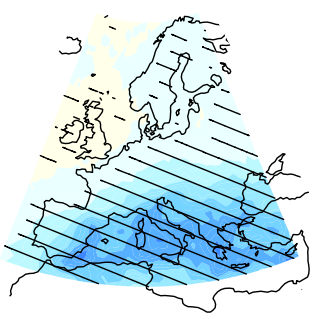

JJA

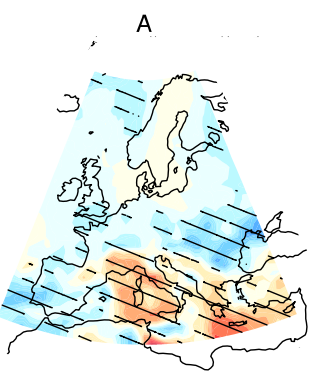

JJA

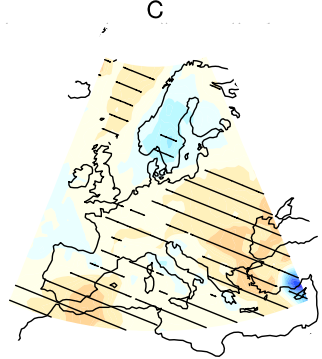

JJA

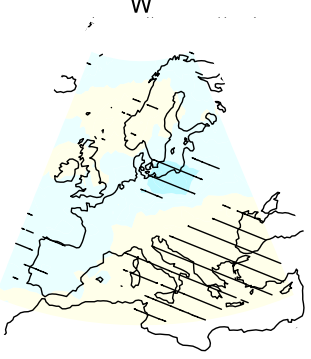

JJA

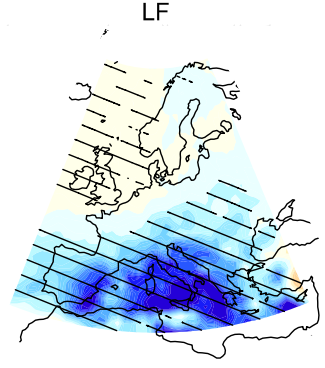

SON

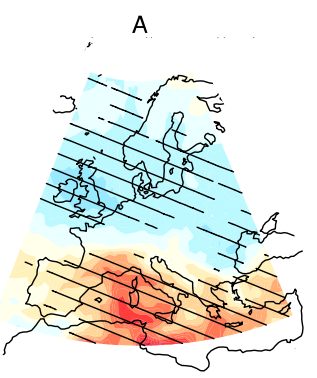

c

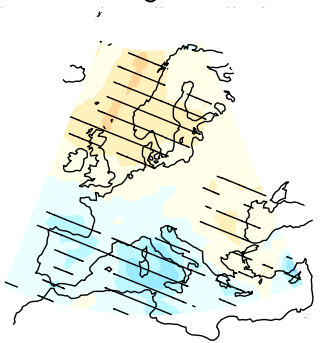

W

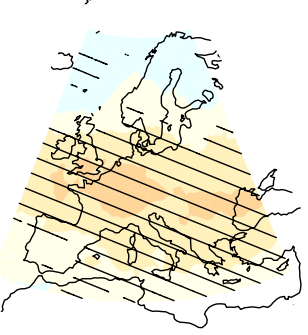

LF

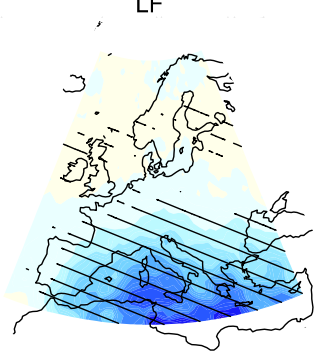

DJF

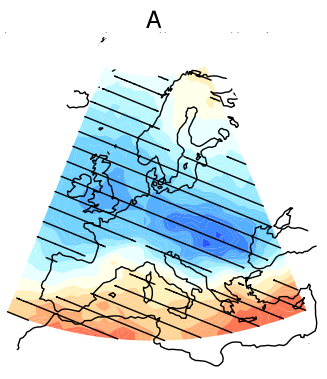

DJF

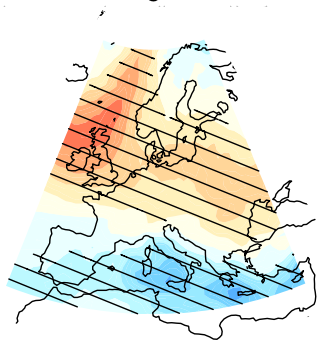

DJF

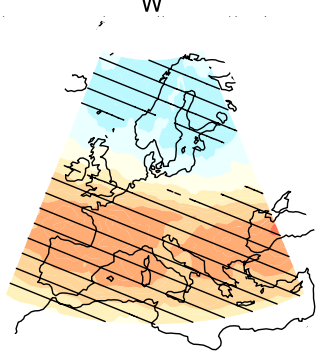

DJF

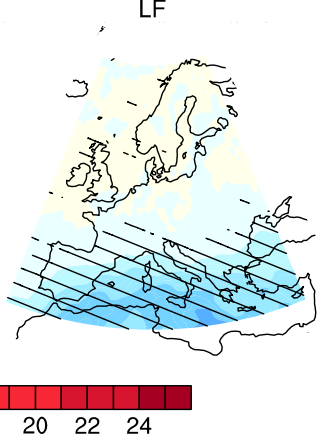

Fig. 2 Differences of relative frequencies (in \%) for the most frequent WT between a multi-model ensemble (MME) and ERA-Interim at the reference period 1986-2005. Stripped areas show the significant differences at 95\%, based on a two-tailed Student's t-test 
generally being able to simulate the main geographical features of WT frequencies as represented by ERA-Interim (Figs. S1, S2), we find differences in the spatial representation among the models when reproducing WT (Fig. 2). For example, the MME overestimates the occurrence of A days in South Europe and underestimates it in North Europe, especially in autumn and winter. The type $\mathrm{C}$ is overestimated by the MME over most of Europe in all seasons, except in autumn and winter where the MME underestimates the number of $\mathrm{C}$ days in South Europe. The MME shows that models also simulate more $\mathrm{W}$ through the whole year, especially in winter over Central and South Europe. The largest differences are found for LF, particularly over Southeast Europe (e.g., Mediterranean area), where the MME does not reproduce the large portion of LF days shown by ERA-Interim. In particular, the frequency bias shows a north-south dipole, specially marked in summer and autumn for the type LF. This dipole is also reflected when analysing the seasonal WT frequencies averaged over
North and South Europe separately (Fig. S3). Similar patterns of differences are found for the most frequent types when models are compared against NCEP2 (Fig. S4). For the rest of the WT, in general, we found smaller differences between models and both reanalyses frequencies, which might be due to their lower occurrence. (Figs. S5, S6).

Figure 3 shows Taylor diagrams for seasonal frequencies of the most frequent patterns over Europe (A, C, W and LF). For A, correlations are particularly low in spring and autumn, and the spread in the normalised Std is larger in spring, which suggest a poorer performance when comparing to winter or summer. Indeed, there are evident differences among models. For example, the lower correlation values and larger Std $(>1)$ in some models indicate poor agreement (e.g., BNU-ESM, MIROC-ESM, GISS-E2-R or IPSL-CM5A-LR), while other models are close to ERAInterim with higher correlations and lower spread for Std (e.g., CESM1-CAM5, EC-EARTH and the MME). The best performance of the type $\mathrm{A}$ is apparent in summer,
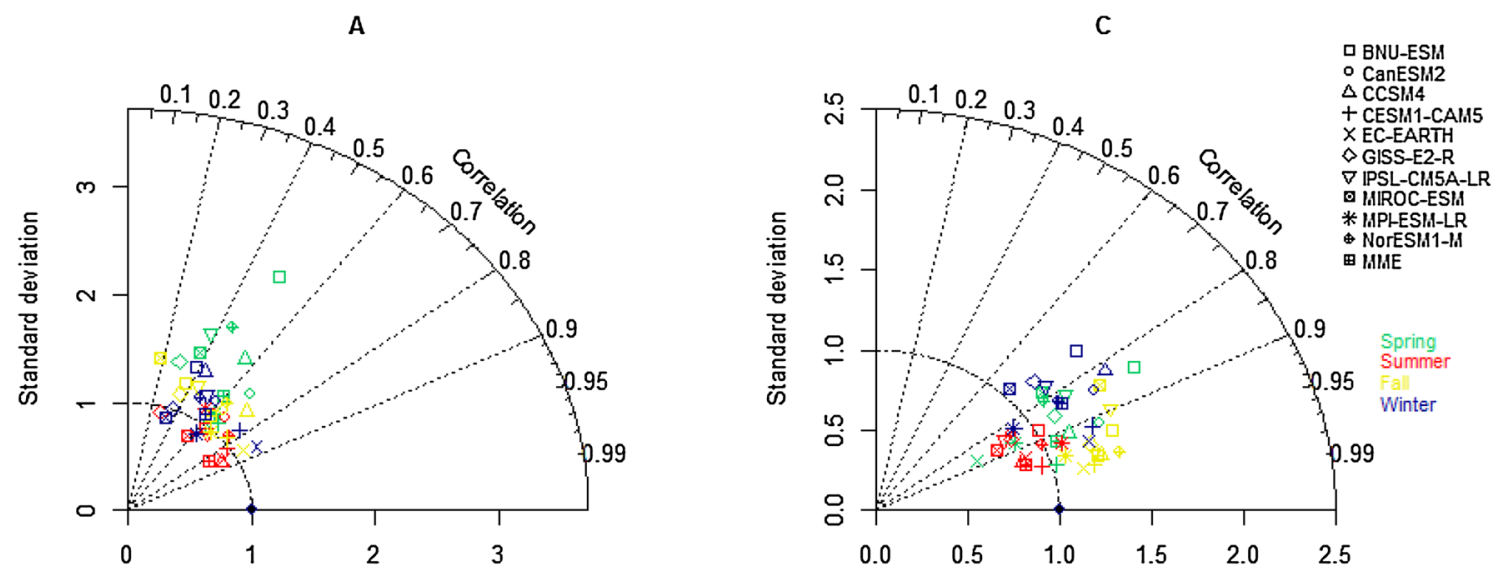

W

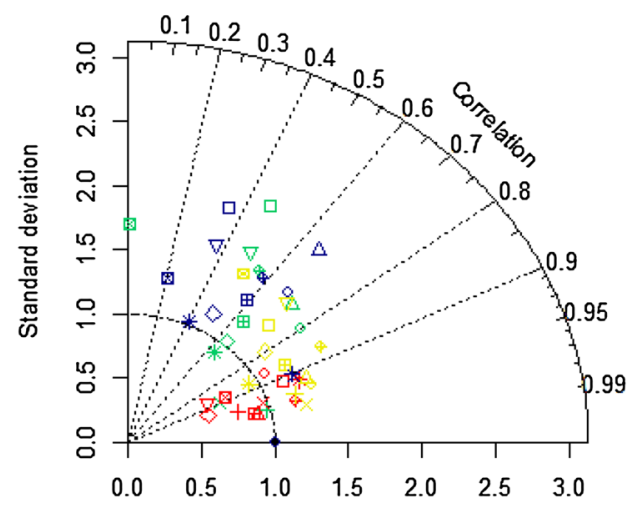

Fig. 3 Taylor diagrams for assessing the CMIP5 skill in simulating seasonal frequencies averaged over the reference period of the 4 most frequent types: Anticyclonic (A, left-top), Cyclonic (C, right-top), 
where models are near to the observed (ERA-Interim) reference point.

Correlations are higher for the type $\mathrm{C}$ than those obtained for the type A, ranging between 0.6 and 0.98 for all seasons. There is also a significant spread among the models in Std, and we notice that most of the models overestimate the $\mathrm{C}$, except in summer. Models such as EC-EARTH, CESM1-CAM5, NorESM1-M and the MME show higher correlations, which suggests a better agreement with the reanalysis. Large discrepancies for the type $\mathrm{C}$ are found for some models in spring and winter (e.g., BNUESM or MIROC-ESM).

For $\mathrm{W}$ there is a large spread among the models, mostly in winter and spring with a lowest correlation values and highest Std (e.g., MIROC-ESM, BNU-ESM or IPSLCM5A-LR). Overall, models show a better agreement in representing $\mathrm{W}$ in summer, although in some specific cases a good performance is also found in spring (e.g., CESM1-CAM5).

In the case of LF, it is worth noting that correlation values are particularly high, but there are serious discrepancies between models and ERA-Interim in terms of Std $(<1)$, and all models are far from the reanalysis, underestimating the frequency of LF. This is consistent with the main features described by the spatial differences between the simulated and the LF type obtained from the reanalysis.

For the remaining WT (N, NE, E, S, SE, SW and NW), the models vary in their performance (not shown). For instance, models differ considerably from reanalyses for the specific directional types $\mathrm{E}$ and SE, and negative correlations where found in spring and winter for some models (e.g., BNU-ESM, MIROC-ESM). A better skill of the models is found for $\mathrm{N}$ and $\mathrm{S}$ in all seasons, except for $\mathrm{S}$ in winter, where models show an overestimation with larger Std values $(>1)$.

In order to further investigate the model performance, the SI is calculated to estimate the spatial differences between each model and the reanalysis by using all $11 \mathrm{WT}$ (Pérez et al. 2014). Figure 4 depicts the SI for each model and season, where the lowest values indicate a better skill for representing frequencies of WT. The results reveal that models perform better in summer and autumn compared to spring and winter over most of Europe. Specifically, the lowest values of SI (close to 0) are found in North and Central Europe (e.g., CESM1-CAM5). However, we notice that all models show the largest values of SI in summer in some grid points over the Mediterranean basin (e.g., CanESM2, GISS-E2-R and MIROC-ESM with SI >2). In spring and winter, some models show a low skill over Europe (e.g., BNU-ESM, IPSL-CM5A-LR, CCSM4 or MIROC-ESM), especially over Southeast Europe. The MME presents a relatively high skill over most of Europe, but also reflects that models do not capture synoptic variability in the
Southeastern regions in terms of WT frequencies. Since the SI is computed by considering all 11 types together, this feature might be related to the fact that models have discrepancies in reproducing some specific WT (e.g., significant differences found for $\mathrm{LF}$ ), and due to the low variability of the pressure input field over this region. Furthermore, we found that most of the models represent pressure gradients more pronounced than the reanalysis, and the MME overestimated the average of MSLP over this region (Fig. S7). As a result, the number of LF days is lower in the models when comparing with the number of LF in the reanalyses. Similar results have been reported in previous works when analysing pressure fields in GCMs and reanalyses datasets (Donat et al. 2010b; Demuzere et al. 2009b).

In summary, the analysis of the CMIP5 models reveals that the models are generally able to reproduce the main features of frequencies of synoptic types, although with considerable differences between WT (e.g., severe underestimation of LF type, especially in summer and a general overestimation of $\mathrm{C}$ and $\mathrm{W}$ types in winter). Our results suggest that the skill not only depends on the model, and the season, but also we find an important geographical dependence (e.g., poor performance over Southeast Europe). Interestingly, we noticed that the more skilful models are those with a higher resolution (e.g., EC-EARTH, CESM1CAM5) compared to models with coarser resolution (e.g., BNU-ESM or MIROC-ESM). This is in agreement with El Kenawy and McCabe (2016), who pointed out that the increasing spatial resolution of the CMIP5 models might have an impact in reproducing circulation patterns.

However, it is important to emphasize that the effect of the resolution is not clear, for instance, the CCSM4 model with high resolution showed a lower skill particularly in winter (compared to the more skilful models). The large variety of physics parametrisation schemes used by the CMIP5 models has been suggested to be an additional source of uncertainty that should be considered when comparing different sets of models (Taylor et al. 2012; Sillmann et al. 2013). Therefore, further investigation would be required for a better understanding of the role of model resolution. On the other hand, our results also confirm that using a multi-model ensemble diminishes the effects of individual models and in general, it shows a reasonable good agreement than individual models with observations (Pérez et al. 2014).

\subsection{Future simulated changes of WT frequency}

Our analysis of future projections is based on the differences between the frequencies of WT for each model from historical simulations and future scenario runs. Figure 5 shows projected changes of the seasonal frequencies for the most frequent types using the multi-model ensemble for the 

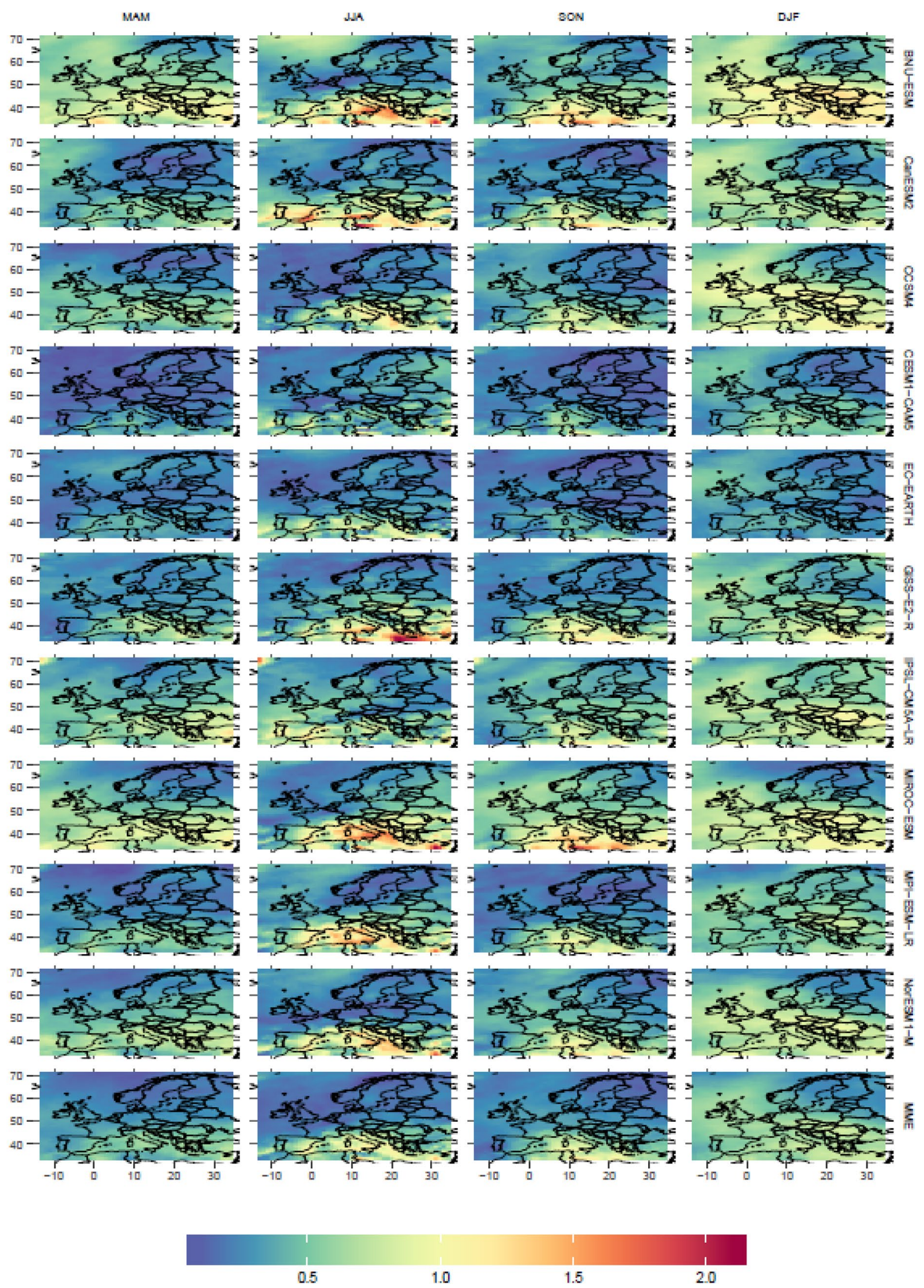

Fig. 4 Spatial maps of the scatter index (SI) showing the skill of CMIP5 models in reproducing WT in the reference period compared to ERAInterim. SI is computed for each season (columns) and model (rows). Lower values of SI indicate a better model performance 


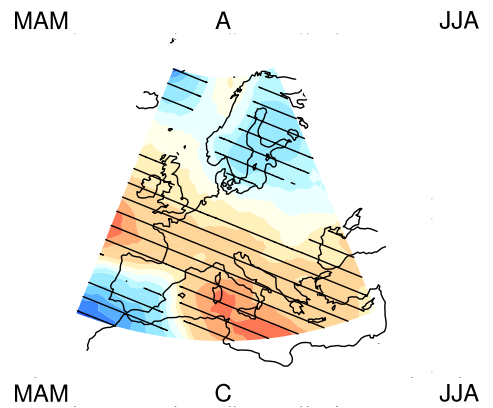

MAM

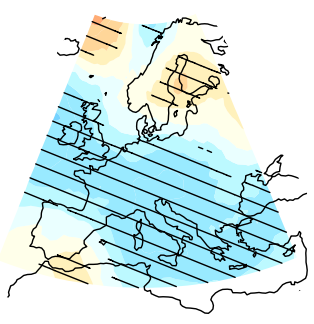

MAM

W

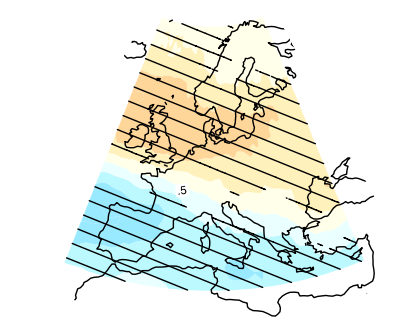

MAM

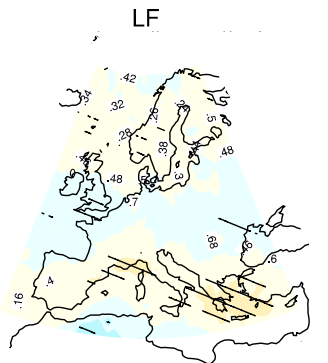

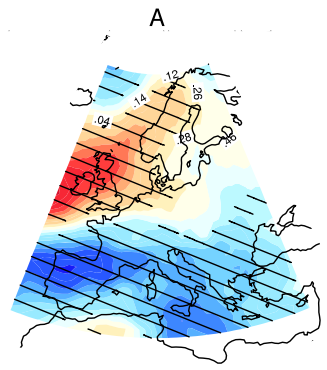

SON

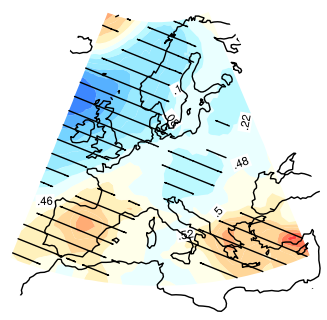

W

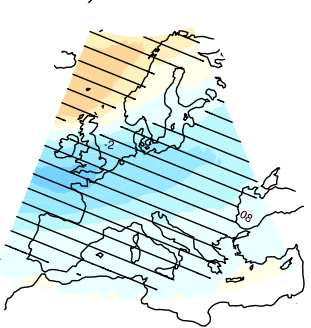

JJA

LF

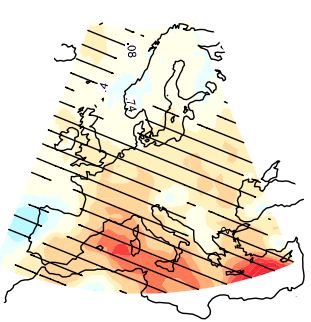

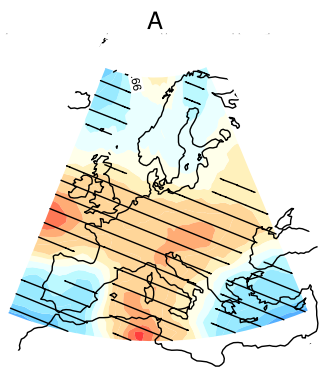

C

DJF
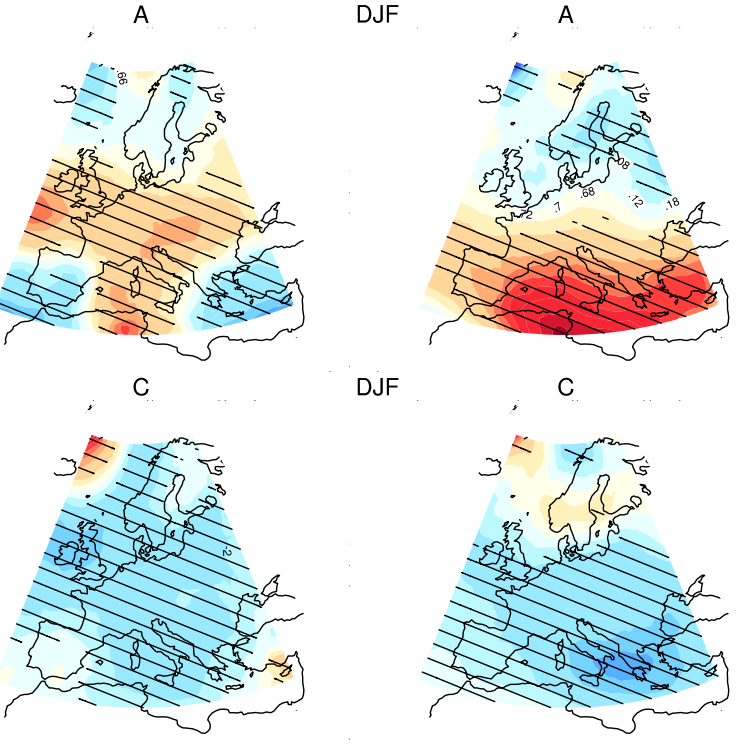

W

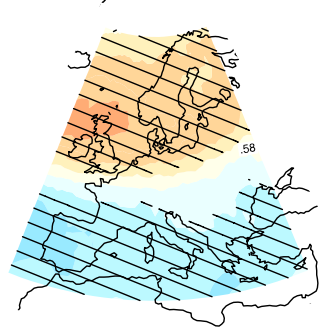

LF

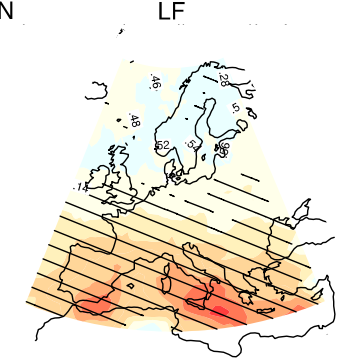

C

DJF

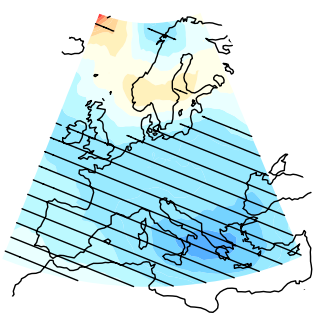

W

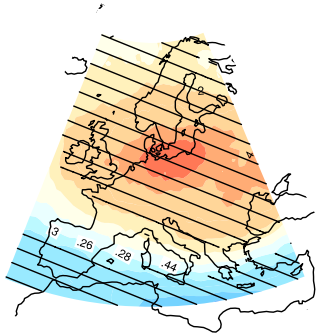

DJF

LF

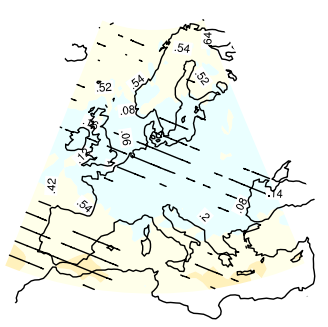

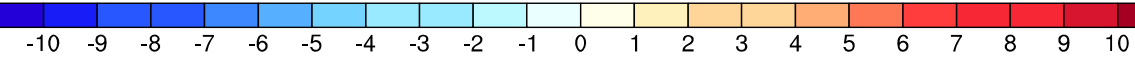

Fig. 5 Differences of relative frequencies (in \%) for the most frequent weather types between the multi-model ensemble mean (MME) in the reference period and the late twenty-first century period 2081-

late period 2081-2100 with respect to the reference period. A Student's t-test shows the areas, which are statistically significant in terms of changes of WT frequencies.

In winter, results show a dipole of changes in the frequency of the type A, with an increase over the South, most pronounced over the Mediterranean area, and a decrease in the North. The opposite pattern is found for the type $\mathrm{W}$ with increasing westerly flow conditions over Central and North Europe in the future. In general, the MME indicates a decrease of $\mathrm{C}$ days over most of Europe in the coming winters, with the Southeast of Europe being most affected by this reduction. Similar features are found in autumn,
2100 of the RCP85 scenario. Stripped areas show significant differences at the $95 \%$ confidence level based on a two-tailed Student's t-test

although there is a slight decrease in the number of A days in the Southwest of the Iberian Peninsula and over Eastern Mediterranean. The decrease of $\mathrm{C}$ is projected over most of Europe, while for the type $\mathrm{W}$ there is a similar dipole than in winter and there is an increase over Central and North Europe and a decrease over South Europe. Furthermore, in autumn the MME shows a significant increase of LF conditions over South Europe.

In spring, there are slight changes in terms of magnitude when comparing with the rest of the seasons, although they are statistically significant for the most frequent types. In summer the results show substantial changes for 
some specific types (e.g., A and LF). Specifically, in summer the projected changes of WT show an increase of A days over North Europe, particularly over the British Isles, while there is a decrease in the number of $\mathrm{A}$ days in the South. This pattern is the opposite of the dipole previously described in winter. For the type $\mathrm{C}$, a reduction is found over North Europe and an increase over South Europe.

These results are consistent with previous studies where projections indicated a larger influence of western circulation over Central Europe in future winter and autumn seasons (Demuzere et al. 2009b) and an intensification of easterlies in summer and spring in some specific regions of South Europe, such as the Northwest of the Iberian Peninsula (see Fig. S8) (Lorenzo et al. 2011). Finally, it is interesting to mention that projections also show a significant increase of the type LF over the Mediterranean area in summer. Therefore, situations associated with weak circulation (calm weather) would be expected to become more frequent.

In general, our findings are in agreement with the projected changes in MSLP that indicate an increase of MSLP in summer over the North Atlantic, centred over the British Isles (Collins et al. 2013), while there is a decrease of MSLP over the rest of Europe, especially in the Mediterranean region (Belleflamme et al. 2015). In winter, projections show an increase of MSLP over Western Europe and a reduction over the North (Wilhelm et al. 2016). Here, we found analogue results when analysing the frequency changes in the occurrence of the types $\mathrm{A}$ or $\mathrm{C}$, which particularly describe high and low pressure centres, respectively.

\subsection{Influence of weather types on daily maximum and minimum temperatures}

Figure 6 depicts a comparison between the winter composite maps of average daily Tmax anomalies associated with the most frequent WT obtained for the reanalysis ERAInterim and the MMEs for historical and future RCP8.5 experiments. Overall, the MME from historical runs shows that models are able to reproduce the winter patterns of the relationship between WTs and Tmax anomalies as presented in ERA-Interim. The composites derived from the ERA-Interim show for the type A a dipole of significant Tmax anomalies, which is negative over North Europe, especially over the Northeast, and positive over South Europe. An opposite dipole is shown for $\mathrm{C}$, with positive anomalies over Northeast and negative anomalies over Southwest Europe. These anomalies are statistically significant over most of Europe, except in those transition zones between the positive and the negative anomalies. Warmer temperatures are related to the type $\mathrm{W}$, which is associated with positive anomalies of Tmax over most of Europe.
We find some spatial discrepancies for these types between ERA-Interim and the MME in the reference period. For instance, the MME overestimates the warmer temperatures associated with the $\mathrm{W}$ type over Scandinavia, while the MME slightly underestimates them over Central and Southeast Europe (e.g., Balkans). Negative anomalies are associated with LF over most of Europe in winter, with a peak of colder anomalies of Tmax over Scandinavia that is not well represented by the MME. As expected, colder temperatures are linked to $\mathrm{N}$ over Europe, while warmer temperatures are associated with $\mathrm{S}$, except in some central regions and over the northwest of Scandinavia, where negative anomalies are found. Easterlies (i.e., NE, E and SE) are generally responsible for bringing colder temperatures during winter over Europe. In this case, the MME overestimates the peak of colder temperatures over Scandinavia (Fig. S9).

In summer, we notice that the most frequent types reveal opposite patterns than those that have been previously described for winter (Fig. 7). For instance, A is associated with positive anomalies over Northeast Europe, while in the South the type A is related to negative anomalies. In this case, the MME underestimates the peak of positive anomalies over Scandinavia. For C, the MME also underestimates the colder temperatures over Eastern Europe with respect to the pattern shown in ERA-Interim. Overall, we find significant anomalies for the type $\mathrm{W}$, which is associated with colder temperatures in summer over most of Europe except in the North of Scandinavia and some regions over East Europe, where a peak of positive anomalies is shown. Furthermore, in summer easterlies (e.g., E, SE) bring warmer temperatures over most of Europe, except the northerly component (NE), which is linked to negative Tmax anomalies in central regions. The MME shows some discrepancies in reproducing the highest temperatures associated with easterlies over some regions (i.e., Northwest of the Iberian Peninsula, the British Isles, France or Germany) (Fig. S10).

Overall, the composites for spring and autumn show very similar patterns as for summer for most of the WT (not shown). Although in these seasons, the MME overestimates the warmer anomalies associated to easterlies over some western regions. In addition, we find that the magnitude of the anomalies is smaller when analysing the composites for Tmin for ERA-Interim and MME at the reference period. In this case, the main differences when comparing with the composites for Tmax are found for the types $\mathrm{A}$ and $\mathrm{C}$, in particular for winter and summer (Figs. S11 and S12, respectively).

Focusing on the relationship between WT and Tmax in future climate conditions, the patterns represented by the MME composites for the RCP8.5 scenario do not show considerable changes from those shown for the historical 
A

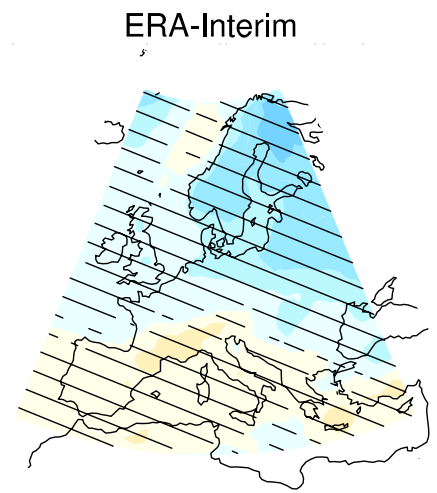

c

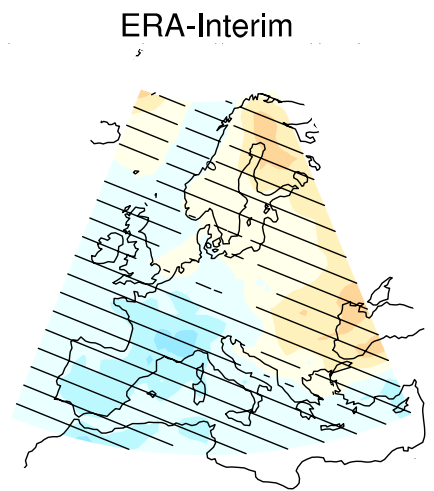

w

ERA-Interim

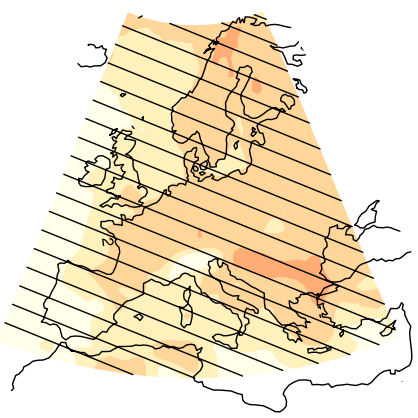

LF

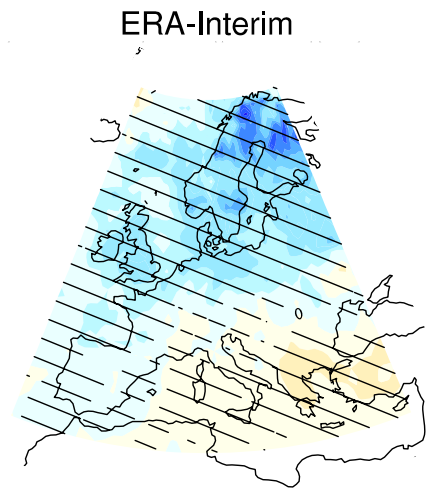

A

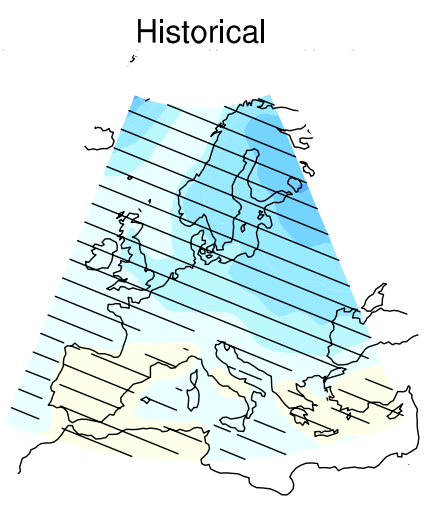

c

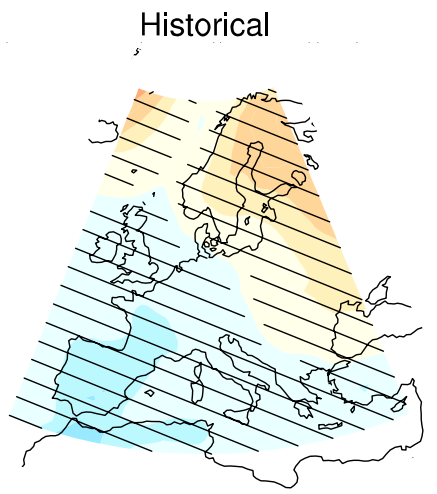

w

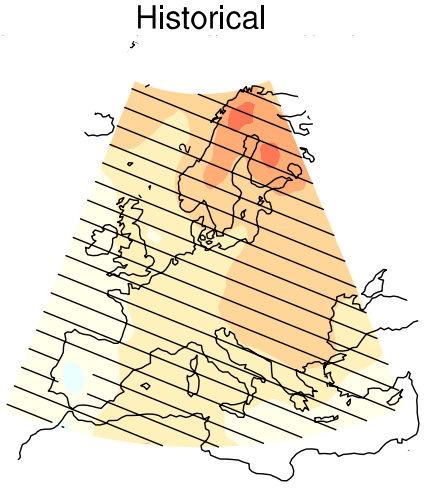

LF

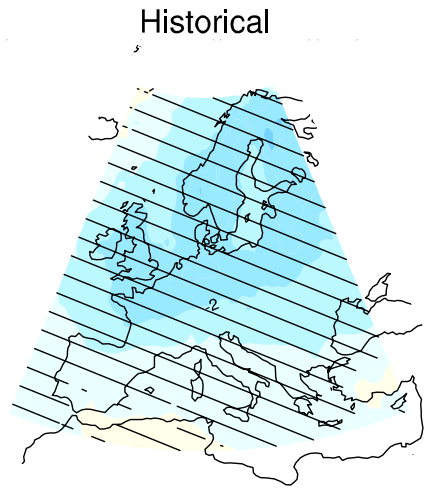

A

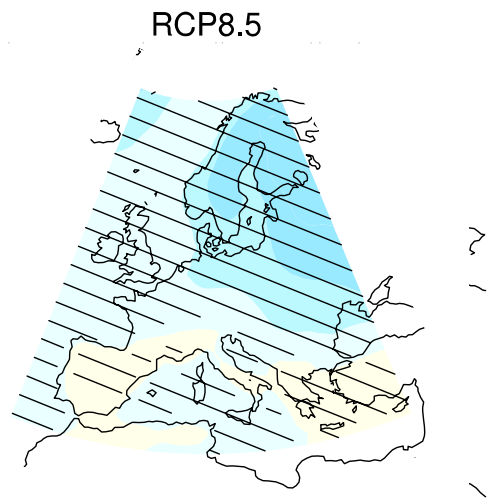

c

RCP 8.5

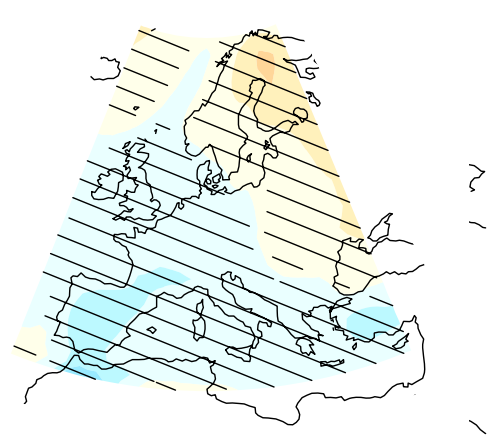

w

RCP8.5

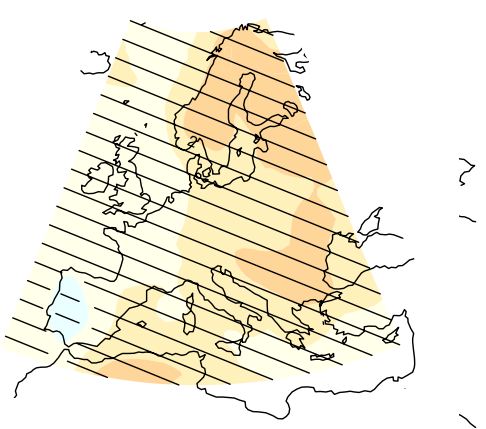

LF RCP8.5

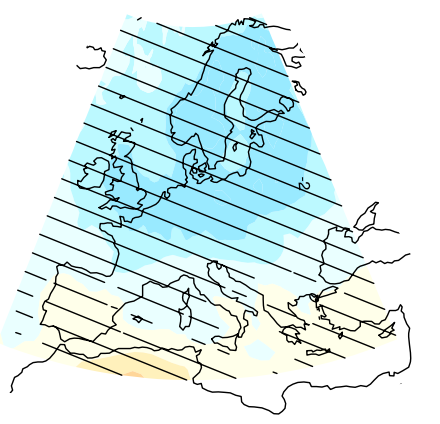

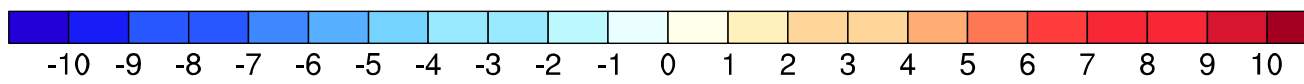

Fig. 6 Composites of winter anomalies of maximum temperatures (in $\mathrm{K}$ ) for the most frequent WT (A, C, W, and LF) derived from ERA-Interim (left) and the MME from historical experiments at the reference period 1986-2005 (middle), and the MME for the late period 2081-2100. Stripped areas show the significant differences at 95\%, based on a two-tailed Student's t-test 
A

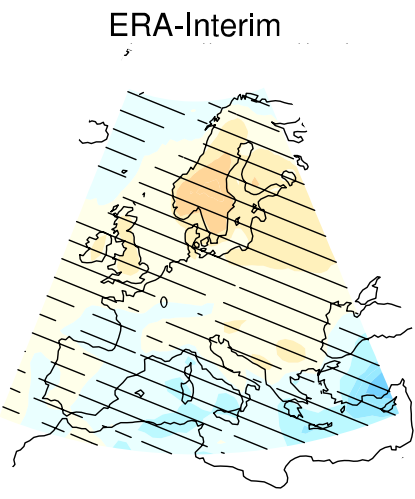

C

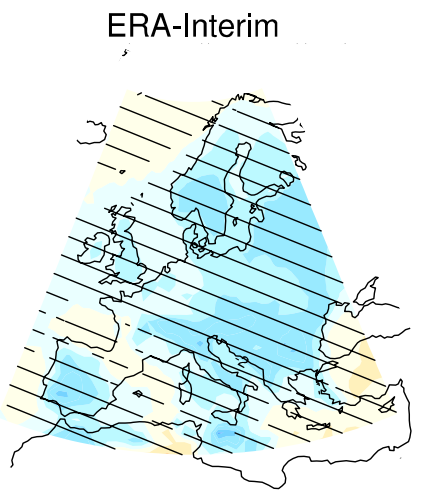

w

ERA-Interim

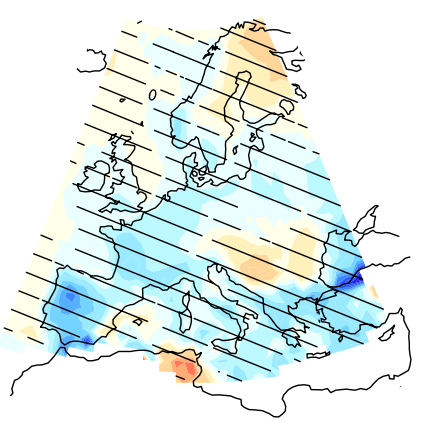

LF

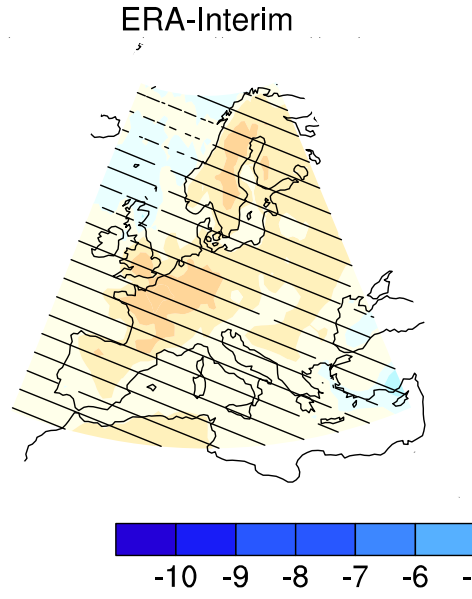

A

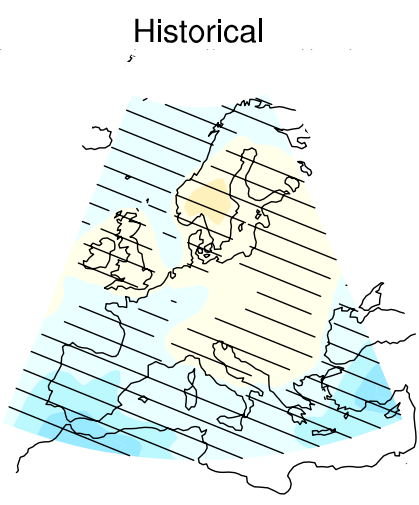

c

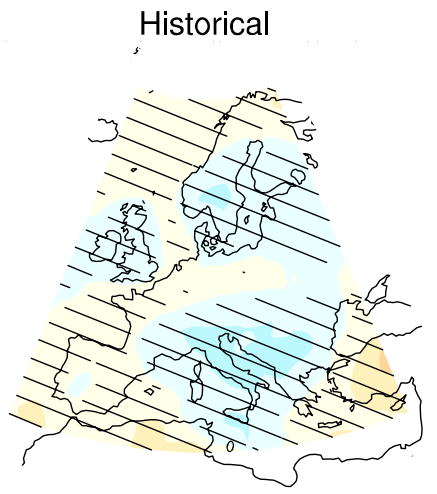

w

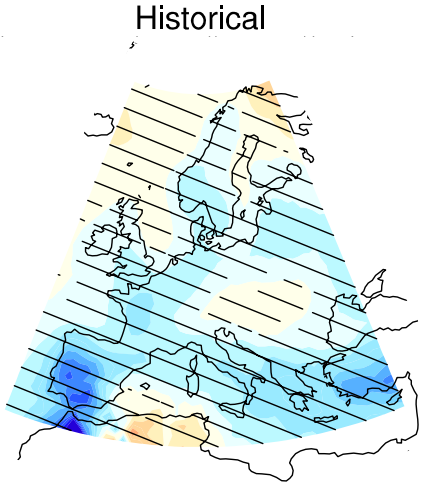

$\mathrm{LF}$

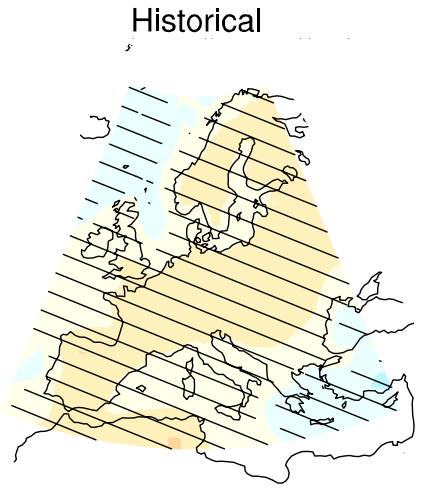

A

RCP8.5

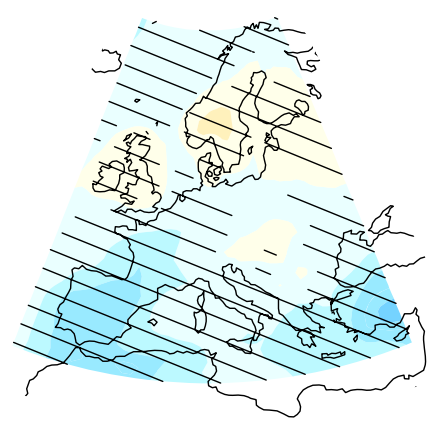

RCP8.5

c

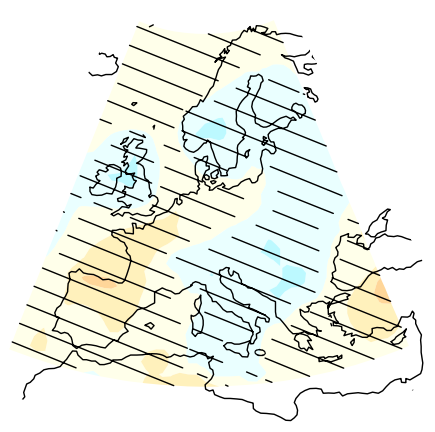

RCP8.5

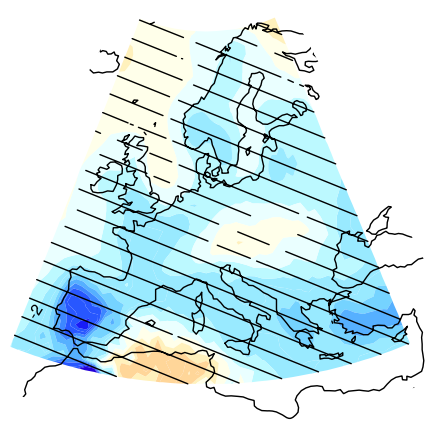

RCP8.5

LF

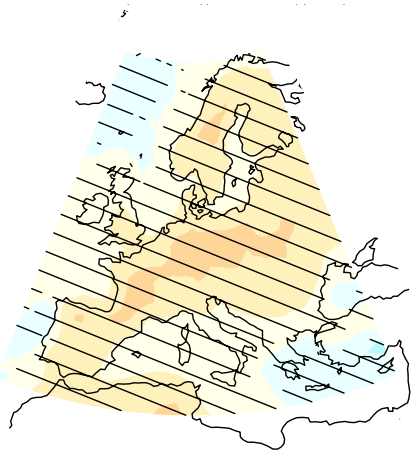

Fig. 7 Composites of summer anomalies of maximum temperatures (in $\mathrm{K}$ ) for the most frequent WT (A, C, W, and LF) derived from ERA-Interim (left) and the MME from historical experiments at the reference period 1986-2005 (middle), and the MME for the late period 2081-2100. Stripped areas show the significant differences at 95\%, based on a two-tailed Student's t-test 
simulations. As depicted in Fig. 6, in winter the projected negative anomalies of Tmax associated to type A are weaker, especially over Northeast Europe (e.g., North Sea region or Scandinavia). Similarly, projections show weaker negative anomalies of Tmax linked to easterly types (i.e., E, SE and NE) (Fig. S9). Particularly in these regions, projections show a slight decrease in the magnitude of positive anomalies linked to $\mathrm{W}$ and the type $\mathrm{C}$, compared to those shown by the MME at the reference period. In summer, warmer temperatures during days of the $\mathrm{C}$ type can be seen over the western regions (e.g., Iberian Peninsula, France) in RCP8.5. Similarly, warmer temperatures are found for the type LF over most of Europe, especially in some central regions (Fig. 7). Previous studies found a mean surface warming in the North Sea in winter and, also over North and Central Europe in summer (Knutti and Sedláček 2012) from the CMIP5 multi-model ensemble. This is consistent with our patterns of a weaker peak of negative temperature anomalies linked to easterlies in winter (Fig. 6), and warmer temperatures associated to LF in summer (Fig. 7). The projected anomalies of Tmin associated with each WT do not reveal important changes and, in general, similar features of the patterns as in the present are found (Figs. S11, S12).

Overall, our findings are consistent with previous studies that pointed out the link between westerlies and positive temperatures anomalies in form of milder winter conditions mostly over Central Europe (Riediger and Gratzkil 2014). Easterlies are related to negative anomalies in winter, bringing cold and dry continental air masses especially into Northeast and Central Europe during winter months. During the rest of the year, the easterly types are linked to warm temperatures, specifically over the western regions in summer and autumn. The LF type is also responsible for warmer temperatures over South Europe. In this context, the projected changes of WT frequencies show an increase in the frequency of easterlies and low flow situations over those regions (e.g., Iberian Peninsula and the Mediterranean area) and therefore, more frequent warm days would be expected. Moreover, given the positive relationship between westerlies and temperature in winter, we may assume warmer average temperatures over Central and Northeast Europe due to the expected increase in the frequency of westerly situations that we find for the MME from the RCP8.5 scenario. Similarly, due to the increase of anticyclonic situations over South Europe under the RCP8.5 scenario milder winters could be expected there.

\subsection{Weather types variations and temperature changes}

As mentioned in Sect. 3, previous studies suggested that global warming might induce changes in circulation patterns that are linked to European temperatures, in terms of their frequencies but also modifying their underlying mechanisms (Belleflamme et al. 2015; Brinkmann 1999). Therefore, it is important to highlight that global warming would influence both, frequency and within-types changes (Cahynová and Huth 2016).

Here, we aim to assess the effect of changes in WT frequency on projected temperatures, by using a simple decomposition (Barry and Perry 1973) that estimates the temperature changes between future and present as a contribution of two terms: the frequency-related and withintypes variations (see Sect. 3). We examine differences in maximum and minimum temperatures between the future period 2081-2100 and the present 1985-2006.

Figure 8 depicts the differences of Tmax between the future and the present period, along with the terms of the decomposition (cf. Eq. 2). Projected temperature changes show considerable variation among the CMIP5 models, but all models project a regional warming with respect to present climate (1986-2005), and specifically for the RCP8.5 scenario with the greatest global mean temperature increase (Wilhelm et al. 2016). Here, we find that the MME illustrates this warming specially in summer. In particular, the projections of maximum temperatures indicate a westeast gradient warming, more pronounced in summer over the eastern regions. Moreover, in summer and autumn, we also find a north-south gradient, which appears stronger in summer over some southern regions (e.g., the Iberian Peninsula).

The decomposition analysis for Tmax shows that the contribution of the frequency-related changes is very small compared to the within-type variations. A slight negative contribution of the frequency-related changes can be seen in winter over the Mediterranean area, and over Central Europe in spring. Our results show that within-type variations clearly dominate over frequency-related changes in European maximum temperatures variations. In this sense, we found similar results when using Tmin (Fig. S13). Additionally, the percentages of the whole temperature change (i.e., the combined effect of frequency-related and withintypes changes) that can be individually attributed to each WT reveal that the larger contributions correspond to the most frequent types (i.e., A, C, W and LF) (not shown). For instance, the type A is the most dominant WT (in terms of $\%$ ) of Tmax changes throughout the year over Central and South Europe, while LF appears to have more influence in summer and autumn over Southwest Europe (e.g., over the Mediterranean area). The largest contribution of $\mathrm{W}$ is found in winter over Central Europe (e.g., North France, Belgium, Netherlands and Germany).

Our findings are in agreement with previous studies that indicated the within-type variations are in general more important than the frequency-related changes for European temperatures (e.g., Jones and Lister 2009; 


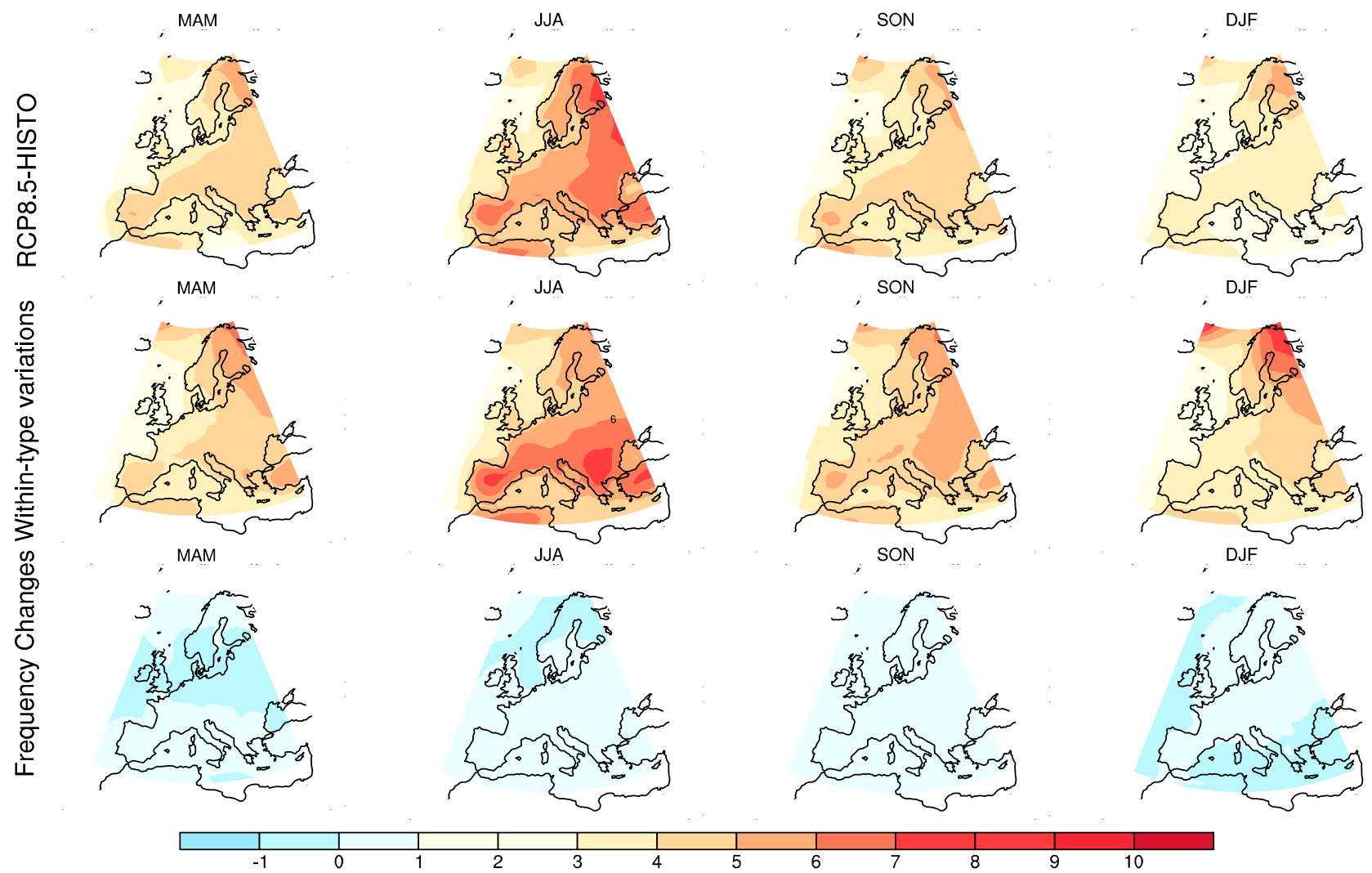

Fig. 8 Seasonal differences of average of Tmax (in K) for the multi-model ensemble between the late period 2081-2100 and the present 19862005 (top), and seasonal Tmax changes ascribed to within-types variations (middle) and frequency-related changes of WT (bottom)

Küttel et al. 2011). By using a different approach, Cattiaux et al. (2013) pointed out that the major source of temperature differences would arise from non-dynamical processes, and Goubanova et al. (2010) also found that changes in European temperatures may be explained due to the different amplitudes of warming among the weather types. As mentioned, within-type variations may be due to different causes, such as changing dynamic properties of the weather types themselves, subgrid-scale processes, or changes in the climatic boundary conditions (Beck et al. 2007; Küttel et al. 2011). In particular, the latter have been assigned to variations in those areas where advection strongly influences specific weather types (Jones et al. 1999). Earlier studies pointed out that anthropogenic global warming might induce such changed climatic boundary conditions, however a significant trend in that direction has not been found (Beck et al. 2007; Houghton et al. 2001). Here, we are mainly focused on evaluating the effect of changes in WT frequencies on maximum and minimum temperature, therefore further investigations are required to evaluate both dynamic and physics contributions that induce withintype variations.

\section{Summary and conclusions}

A geographically extended implementation of the objective weather type classification of Jenkinson and Collison (1977) derived from the traditional Lamb WT has been presented in this study. On the basis of the JC procedure, we applied a moveable mask of 16 points at every grid point over gridded fields of climate model output, avoiding the Poles and the tropical regions between $0^{\circ}-15^{\circ} \mathrm{N}(\mathrm{S})$. We have, thus, provided a gridded WT classification of the JC, which is a suitable procedure to assess synoptic conditions over multiple grid points. Nevertheless, the present study has focused on the European region allowing us to refer to a large amount of literature applying JC classification to this region in order to compare and discuss our findings. With the gridded JC classification presented here, we were able to assess the capability of a set of current state-ofthe-art CMIP5 models to represent realistic synoptic patterns. To this aim, the models' performance was evaluated by using two reanalyses, ERA-Interim and NCEP2. Model simulations from three different experiments, namely preindustrial, historical and the RCP8.5 future scenario have been used, and the multi-model ensemble mean for each 
experiment was computed. Furthermore, we have analysed the influence of WT on maximum and minimum European temperatures.

The multi-model ensemble (MME) mean of historical runs indicates that models are generally capable of reproducing patterns of relative frequencies of WT when comparing with those obtained from both reanalyses (ERAInterim and NCEP2) in the reference period (1986-2005). Four types were most frequent for the reanalyses over Europe throughout the year: Anticylonic (A), Cyclonic (C), Westerly (W) and Low Flow (LF). Despite the relative WT frequencies are simulated reasonably well by the MME, some notable geographical differences were found. The spatial differences between the MME and ERA-Interim in the reference period reveal that in some specific regions, the models do not reproduce WT consistently, such as LF in the Southeast or W in the South. Apart from these spatial differences, our results also show larger discrepancies for particular WT depending on the season (e.g., summer for LF, and winter for W). Moreover, the analysis of model performance reveals that the skill is particularly low for some specific models, particularly those with a coarser resolution (i.e., BNU-ESM, MIROC-ESM), while the more skilful ones show a good agreement with ERA-Interim (EC-EARTH, CESM1-CAM5).

The analysis of projected future changes of WT frequencies using the emission scenario RCP8.5 shows significant changes in the occurrence frequency for some weather types depending on the season, and those changes would have a major effect in some specific regions over South Europe. In particular, the Mediterranean area would be affected by an increase of $\mathrm{A}$ in all seasons, except in summer for which a decreasing number of anticyclonic conditions is projected. On the contrary, our results show an increase of A days in summer over the British Isles, which would suggest drier and warmer summer conditions over this area. Consistently with previous studies (e.g., Van Ulden and van Oldenborgh 2006; Donat et al. 2010b) we found an increased frequency of the type $\mathrm{W}$ especially in winter over Central Europe. The increase of the occurrence of LF days would be directly related with more situations of weak circulation in summer and autumn. Specifically, our results suggest that low flow days would become more frequent over the Mediterranean region, favouring air stagnation situations and likely more episodes of air pollution, consistent with Horton et al. (2012).

The composites maps derived from the anomalies of maximum temperatures reflected most of these features: significant colder anomalies over Southwest Europe and warmer anomalies in Northwest Europe in summer that would be linked to anticyclonic situations. LF days would imply warmer conditions over most of Europe, in particular in summer and autumn. Projected WT frequencies show an intensification of easterlies over Southwest Europe, specifically an increase of NE days in the north west of the Iberian Peninsula in all seasons except winter, consistent with Lorenzo et al. (2011). On the contrary, we find a decrease of westerlies over South Europe, while more frequent westerly types could be expected in North Europe. The projections show that this increase in the occurrence of $\mathrm{W}$ days would specially affect Central and Northeast Europe in winter and autumn. We also show that the dominance of westerlies would be associated with significant positive temperature anomalies.

Finally, by using a simple decomposition scheme, we assess the proportion of variations in European daily maximum and minimum temperatures that is due to changes in the frequency of WT or due to within-type variations. We find that the contribution of frequency-related changes is considerably smaller than within-type variations. Our results suggest that, in general, the projected changes in European temperatures cannot be related to changes in the frequency of the WT, but must rather be attributed to changed characteristics of or links to these weather types. In the context of climate change, that implies that global warming would also affect the characteristics of some weather types over time (i.e., within-type variations) that are associated with warmer temperatures under future conditions. However, further analyses are required to better understand these within-type changes of the weather types.

Acknowledgements We acknowledge the World Climate Research Programme's Working Group on Coupled Modelling for making the CMIP5 model output available. JS is supported by the Research Council of Norway Grant 243953/E10 (ClimateXL). We acknowledge two anonymous reviewers for their useful comments, which have led to important improvements of this paper.

Open Access This article is distributed under the terms of the Creative Commons Attribution 4.0 International License (http:// creativecommons.org/licenses/by/4.0/), which permits unrestricted use, distribution, and reproduction in any medium, provided you give appropriate credit to the original author(s) and the source, provide a link to the Creative Commons license, and indicate if changes were made.

\section{Appendix}

Based on the original catalogue and procedures (Jones et al. 1993), a set of indices associated with the direction and vorticity of geostrophic flow are calculated. These indices are: southerly flow (SF), westerly flow (WF), total flow (F), southerly shear vorticity (ZS), westerly shear vorticity (ZW) and total shear vorticity $(\mathrm{Z})$. They are calculated according to the expressions below: 


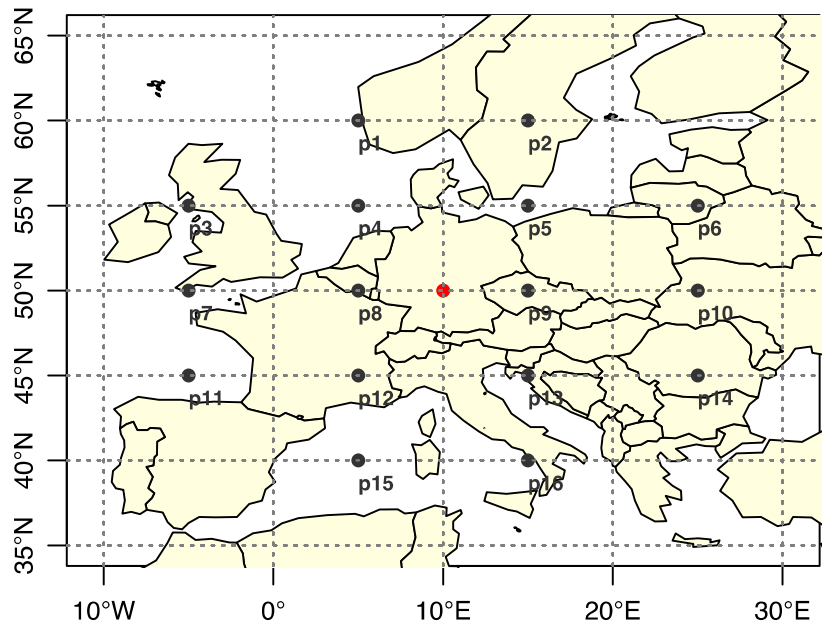

Fig. 9 Example of the 16-grid points distribution around a central point (red) located in Central Europe

$$
\begin{aligned}
\mathrm{WF}= & {[0.5 \cdot(\mathrm{p} 12+\mathrm{p} 13)-0.5 \cdot(\mathrm{p} 4+\mathrm{p} 5)] } \\
\mathrm{SF}= & \mathrm{A} \cdot[0.25 \cdot(\mathrm{p} 5+2 \mathrm{p} 9+\mathrm{p} 13) \\
& -0.25 \cdot(\mathrm{p} 4+2 \mathrm{p} 8+\mathrm{p} 12)] \\
\mathrm{F}= & \left(\mathrm{SF}^{2}+\mathrm{WF}^{2}\right)^{1 / 2} \\
\mathrm{ZS}= & \mathrm{B} \cdot[0.25 \cdot(\mathrm{p} 6+2 \mathrm{p} 10+\mathrm{p} 14) \\
& -0.25 \cdot(\mathrm{p} 5+2 \mathrm{p} 9+\mathrm{p} 13) \\
& -0.25 \cdot(\mathrm{p} 4+2 \mathrm{p} 8+\mathrm{p} 12) \\
& +0.25 \cdot(\mathrm{p} 3+2 \mathrm{p} 7+\mathrm{p} 11)] \\
\mathrm{ZW}= & \mathrm{C} \cdot[0.5 \cdot(\mathrm{p} 15+\mathrm{p} 16)-0.5 \cdot(\mathrm{p} 8+\mathrm{p} 9)] \\
& -D \cdot[0.5 \cdot(\mathrm{p} 8+\mathrm{p} 9)-0.5 \cdot(\mathrm{p} 1+\mathrm{p} 2)] \\
\mathrm{Z}= & \mathrm{ZS}+\mathrm{ZW}
\end{aligned}
$$

where p1-p16 represent the pressure fields for 16-grid points around the selected central point, for which daily circulation is classified (Fig. 9). The flow and vorticity units are geostrophic, expressed as $\mathrm{hPa}$ per $10^{\circ}$ latitude at the latitude defined by the central point chosen. The following expressions represent the constants referred to the relative differences between the grid-point spacing in the east-west and north-south direction (being $\psi$ the latitude of the central point):

$$
\begin{aligned}
& \mathrm{A}=1 / \cos (\psi) \\
& \mathrm{B}=\sin (\psi) / \sin \left(\psi-5^{\circ}\right) \\
& \mathrm{C}=\sin (\psi) / \sin \left(\psi+5^{\circ}\right) \\
& \mathrm{D}=1 / 2\left(\cos ^{2}(\psi)\right)
\end{aligned}
$$

The rules applied to these indices allow 27 types of weather (Table 1), and according to Jones et al. (1993) they can be summarised:
1. Direction of flow was given by tan- $1(\mathrm{WF} / \mathrm{SF}), 180^{\circ}$ being added if WF is positive. The appropriate direction was computed using an eight-point compass, allowing $45^{\circ}$ per sector.

2. If $|\mathrm{Z}|<\mathrm{F}$, flow is essentially straight and correspond to a Lamb pure directional type (eight different cases, according to the directions of the compass).

3. If $|Z|>2 F$, the pattern was considered to be of a pure cyclonic type if $Z>0$, or of a pure anticyclonic type if $\mathrm{Z}<0$.

4. If $\mathrm{F}<|\mathrm{Z}|<2 \mathrm{~F}$, flow was considered to be of a hybrid type and is therefore characterized by both direction and circulation $(8 \times 2$ different types).

5. If $\mathrm{F}<6$ and $\mathrm{Z}<6$, there is a light indeterminate flow, corresponding to Lamb's unclassified type U.

\section{References}

Barnes EA, Polvani LM (2015) CMIP5 projections of Arctic amplification, of the North American/North Atlantic circulation, and of their relationship. J Clim 368-28:5254-5271. doi:10.1175/ JCLI-D-14-00589.1

Barry RG, Perry AH (1973) Synoptic climatology. Methuen, London

Beck C, Jacobeit J, Jones PD (2007) Frequency and within-type variations of large-scale circulation types and their effects on lowfrequency climate variability in Central Europe since 1780. Int J Climatol 27:473-491

Belleflamme A, Fettweis X, Lang C, Erpicum M (2013) Current and future atmospheric circulation at $500 \mathrm{hPa}$ over Greenland simulated by the CMIP3 and CMIP5 global models. Clim Dyn 41:2271-2278. doi:10.1007/s00382-012-1538-2

Belleflamme A, Fettweis X, Erpicum M (2015) Do global warming-induced circulation pattern changes affect temperature and precipitation over Europe during summer? Int J Climatol 35:1484-1499

Boé J, Terray L, Habets F, Martin E (2006) A simple statisticaldynamical downscaling scheme based on weather types and conditional resampling. J Geophys Res 111:D23106. doi:10.1029/2 005JD006889

Brinkmann WAR (1999) Within-type variability of $700 \mathrm{hPa}$ winter circulation patterns over the Lake Superior Basin. Int J Climatol 19:41-58

Buishand TA, Brandsma T (1997) Comparison of circulation classification schemes for predicting temperature and precipitation in the Netherlands. Int J Climatol 17:875-889

Cahynová M, Huth R (2016) Atmospheric circulation influence on climatic trends in Europe: an analysis of circulation type classifications from the COST733 catalogue. Int J Climatol 36:2743-2760

Casado M, Pastor M (2012) Use of variability modes to evaluate AR4 climate models over the Euro-Atlantic region. Clim Dyn 38: 225-237. doi:10.1007/s00382-011-1077-2

Cattiaux J, Vautard R, Cassou C, Yiou P, Masson-Delmotte V, Codron F (2010) Winter 2010 in Europe: a cold extreme in a warming climate. Geophys Res Lett 37:L20704. doi:10.1029/2010GL044613

Cattiaux J, Douville H, Peings Y (2013) European temperatures in CMIP5: origins of present-day biases and future uncertainties. Clim Dyn 41:2889-2907. doi:10.1007/s00382-013-1731-y 
Chen D (2000) Monthly circulation climatology for Sweden and its application to a winter temperature case study. Int J Climatol 20:1067-1076

Chen ZH, Cheng SY, Li JB, Guo XR, Wang HY, Chen DS (2008) Relationship between atmospheric pollution processes and synoptic pressure patterns in northern China. Atmos Environ 42:6078-6087

Collins M, Knutti R, Arblaster J, Dufresne J-L, Fichefet T, Friedlingstein P, Gao, Gutowski WJ, Johns T, Krinner G, Shongwe M, Tebaldi C, Weaver AJ, Wehner M (2013) Long-term climate change: projections, commitments and irreversibility. In: Stocker TF, Qin D, Plattner GK, Tignor M, Allen SK, Boschung J, Nauels A, Xia Y, Bex V, Midgley PM (eds) Climate change 2013: the physical science basis. Contribution of working group I to the fifth assessment report of the intergovernmental panel on climate change. Cambridge University Press, Cambridge

Comrie AC (1992) An enhanced synoptic climatology of ozone using a sequencing technique. Phys Geogr 13:53-65

Conway D, Wilby RL, Jones PD (1996) Precipitation and air flow indices over the British Isles. Clim Res 7:169-183

Cortesi N, Trigo RM, González-Hidalgo JC, Ramos AM (2013) Modelling monthly precipitation with circulation weather types for a dense network of stations over Iberia. Hydrol Earth Syst Sci 17:665-678. doi:10.5194/hess-17-665-2013

Dee DP et al (2011) The ERA-Interim reanalysis: configuration and performance of the data assimilation system. Quart J R Meteor Soc 137:553-597

Della-Marta PM, Luterbacher J, von Weissenfluh H, Xoplaki E, Brunet M, Wanner H (2007) Summer heat waves over western Europe 1880-2003, their relationship to large-scale forcings and predictability. Clim Dyn 29:251-275

Demuzere M, Trigo RM, Vila-Guerau de Arellano J, van Lipzig NPM (2009a) The impact of weather and atmospheric circulation on $\mathrm{O} 3$ and PM10 levels at a rural mid-latitude site. Atmos Chem Phys 9:2695-2714

Demuzere M, Werner M, van Lipzig NPM, Roeckner E (2009b) An analysis of present and future ECHAM5 pressure fields using a classification of circulation patterns. Int J Climatol 29:17961810. doi:10.1002/joc. 1812

Dessouky TM, Jenkinson AF (1977) An objective daily catalogue of surface pressure, flow and vorticity indices for Egypt and it's use in monthly rainfall forecasting. Meteorol Res Bull $11: 1-25$

Donat MG, Leckebusch GC, Pinto JG, Ulbrich U (2010a) Examination of wind storms over Central Europe with respect to circulation weather types and NAO phases. Int J Climatol 30(9):12891300. doi:10.1002/joc. 1982

Donat MG, Leckebusch GC, Pinto JG, Ulbrich U (2010b) European storminess and associated circulation weather types: future changes deduced from a multi-model ensemble of GCM simulations. Clim Res 42:27-43. doi:10.3354/cr00853

El Kenawy AM, McCabe MF (2016) Future projections of synoptic weather types over the Arabian Peninsula during the twenty-first century using an ensemble of CMIP5 models. Theor Appl Climatol. doi:10.1007/s00704-016-1874-y

El Kenawy AM, McCabe MF, Stenchikov G, Raj J (2014) Multi-decadal classification of synoptic weather types, observed trends and links to rainfall characteristics over Saudi Arabia. Front Environ Sci. doi:10.3389/fenvs.2014.00037

Espinoza PS, Ruiz OM, Vide FJM (2014) Variabilidad y tendencias climáticas en Chile central en el período 1950-2010 mediante la determinación de los tipos sinópticos de Jenkinson y Collison. Bol Asoc Geógr Esp 64:227-247

Goodess C (2000) The construction of daily rainfall scenarios for Mediterranean sites using a circulation type approach to downscaling. $\mathrm{PhD}$ thesis. University of East Anglia
Goodess CM, Jones PD (2002) Links between circulation and changes in the characteristics of Iberian rainfall. Int J Climatol 22:1593-1615

Goodess CM, Palutikof JP (1998) Development of daily rainfall scenarios for southeast Spain using a circulation-type approach to downscaling. Int J Climatol 18:1051-1083

Goubanova K, Li L, Yiou P, Codron F (2010) Relation between largescale circulation and European winter temperature: does it hold under warmer climate? J Clim 23:3752-3760. doi:10.1175/201 OJCLI3166.1

Grimalt M, Tomàs M, Alomar G, Martin-Vide J, Moreno-García MC (2012) Determination of the Jenkinson and Collison's weather types for the western Mediterranean basin over the 1948-2009 period. Temp Anal Atmos 26(1): 75-94

Hart M, De Dear R, Hyde R (2006) A synoptic climatology of tropospheric ozone episodes in Sydney, Australia. Int J Climatol 26:1635-1649. doi:10.1002/joc.1332

Horton DE, Harshvardhan, Diffenbaugh NS (2012) Response of air stagnation frequency to anthropogenically enhanced radiative forcing. Environ Res Lett 7:044034. doi:10.1088/1748-9326/7/4/044034

Houghton JT, Ding Y, Griggs DJ, Noguer M, van der Linden PJ, Dai X, Maskell K, Johnson CA (eds) (2001) Climate change 2001: the scientific basis. Cambridge University Press, Cambridge

Huth R (2000) A circulation classification scheme applicable in GCM studies. Theor Appl Climatol 67:1-18

Huth R, Beck C, Philipp A, Demuzere M, Ustrnul Z, Cahynová M, Kyselý J, Tveito OE (2008) Classifications of atmospheric circulation patterns. Ann N Y Acad Sci 1146(1):105-152

Huth R, Beck C, Kučerová M (2016) Synoptic-climatological evaluation of the classifications of atmospheric circulation patterns over Europe. Int J Climatol 36:2710-2726

Jacob DJ, Winner DA (2009) Effect of climate change on air quality. Atmos Environ 43:51-63

Jenkinson AF, Collison FP (1977) An initial climatology of gales over the North Synoptic climatology. Branch Memorandum 62, UK Met. Office, Bracknell, p 18

Jiang N (2010) A new objective procedure for classifying New Zealand synoptic weather types during 1958-2008. Int J Climatol 31:863-879. doi:10.1002/joc. 2126

Jones PD, Lister DH (2009) The influence of the circulation on surface temperature and precipitation patterns over Europe. Clim Past 5:259-267

Jones PD, Hulme M, Briffa KR (1993) A comparison of Lamb circulation types with an objective classification scheme. Int J Climatol 13:655-663

Jones PD, Horton EB, Folland CK, Hulme M, Parker DE, Basnett TA (1999) The use of indices to identify changes in climatic extremes. Clim Change 42:131-149

Kallos G, Kassomenos P, Pielke RA (1993) Synoptic and mesoscale weather conditions during air pollution episodes in Athens, Greece. Bound Layer Meteorol 62:163-184

Kanamitsu M, Ebisuzaki W, Woollen J, Yang SK, Hnilo J, Fiorino M, Potter GL (2002) NCEP-DOE AMIP-II reanalysis (R-2). Bull Am Meteorol Soc 83:1631-1643

Kassomenos P (2010) Synoptic circulation control on wild reoccurrence. Phys Chem Earth 35:544-552

Kassomenos PA, Gryparis A, Samoli E, Katsougianni K, Lykoudis S, Flocas H (2001) Atmospheric circulation types and daily mortality in Athens, Greece. Environ Health Perspect 109:591-596

Knutti R, Sedláček J (2012) Robustness and uncertainties in the new CMIP5 climate model projections. Nat Clim Change 3:369-373

Küttel M, Luterbacher J, Wanner H (2011) Multidecadal changes in winter circulation-climate relationship in Europe: frequency variations within-type modifications long-term trends. Clim Dyn 36:957-972. doi:10.1007/s00382-009-0737-y 
Lai IC (2010) The relationship between tropospheric ozone and atmospheric circulation in Taiwan. $\mathrm{PhD}$ thesis. University of East Anglia

Lamb HH (1972) British Isles weather types and a register of daily sequence of circulation patterns, 1861-1971. Geophysical Memoirs 116. Great Britain Meteorological Office. H. M. Stationary Office, London

Lee C (2015) The development of a gridded weather typing classification scheme. Int J Climatol 35:641-659

Linderson ML (2001) Objective classification of atmospheric circulation over southern Scandinavia. Int J Climatol 21:155-169

Liwei JLA, Weijing LI, Chen D, Xiaocun AN (2006) A monthly atmospheric circulation classification and its relationship with climate in Harbin. Acta Meteor Sin 20:402-412

Lorenzo MN, Taboada JJ, Gimeno L (2008) Links between circulation weather types and teleconnection patterns and their influence on precipitation patterns in Galicia (NW Spain). Int J Climatol 28(11):1493-1505

Lorenzo MN, Ramos AM, Taboada JJ, Gimeno L (2011) Changes in present and future circulation types frequency in northwest Iberian Peninsula. PLoS One 6(1):e16201. doi:10.1371/journal. pone.0016201

Meehl GA, Covey C, Taylor KE, Delworth T, Stouffer RJ, Latif M, McAvaney B et al (2007) The WCRP CMIP3 multimodel dataset: a new era in climate change research. Bull Am Meteorol Soc 88(9):1383-1394. doi:10.1175/BAMS-88-9-1383

Moss RH, Edmonds JA, Hibbard KA, Manning MR, Rose SK, van Vuuren DP, Carter TR, Emori S, Kainuma M, Kram T et al (2010) The next generation of scenarios for climate change research and assessment. Nature 463:747-756

Otero N, Sillmann J, Schnell JL, Rust HW, Butler T (2016) Synoptic and meteorological drivers of extreme ozone concentrations over Europe. Environ Res Lett 11:024005. doi:10.1088/1748-9326/11/2/024005

Paredes D, Trigo RM, García-Herrera R, Trigo IF (2006) Understanding precipitation changes in Iberia in early spring: weather typing and storm-tracking approaches. J Hydrometeor 7:101-113

Peña-Angulo D, Trigo RM, Cortesi N, González-Hidalgo JC (2016) The influence of weather types on the monthly average maximum and minimum temperatures in the Iberian Peninsula. Atmos Res 178-179:217-230

Pérez J, Menendez M, Mendez F, Losada I (2014) Evaluating the performance of CMIP3 and CMIP5 global climate models over the north-east Atlantic region. Clim Dyn 43(9-10):2663-2680

Post P, Truija V, Tuulik J (2002) Circulation weather types and their influence on temperature and precipitation in Estonia. Boreal Environ Res 7:281-289

Riediger U, Gratzkil A (2014) Future weather types and their influence on mean and extreme climate indices for precipitation and temperature in Central Europe. Meteorol Z 23(3):231-252

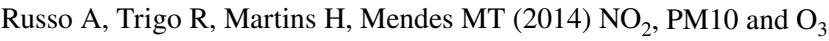
urban concentrations and its association with circulation weather types in Portugal. Atmos Environ 89:768-785
Russo S, Sillmann J, Fischer EM (2015) Top ten European heat-waves since 1950 and their occurrence in the coming decades. Environ Res Lett 10:124003

Sheridan SC (2002) The redevelopment of a weather-type classification scheme for North America. Int J Climatol 22:51-68

Sillmann J, Kharin VV, Zhang X, Zwiers FW, Bronaugh D (2013) Climate extremes indices in the CMIP5 multimodel ensemble: Part 2. Future climate projections. J Geophys Res Atmos 118(6):2473-2493

Spellman G (2000) The use of an index-based regression model for precipitation analysis on the Iberian Peninsula. Theor Appl Climatol 66:229-239

Spellman G (2015) An assessment of the Jenkinson and Collison synoptic classification to a continental mid-latitude location. Theor Appl Climatol. doi:10.1007/s00704-015-1711-8

Tang L, Rayner D, Haeger-Eugensson M (2011) Have meteorological conditions reduced $\mathrm{NO}_{2}$ concentrations from local emission sources in Gothenburg? Water Air Soil Pollut 221:275-286

Taylor KE (2001) Summarizing multiple aspects of model performance in a single diagram. J Geophys Res Atmos 106(D7):71837192. doi:10.1029/2000JD900719

Taylor KE, Stouffer RJ, Meehl GA (2012) An overview of CMIP5 and the experiment design. Bull Am Meteorol Soc 93:485-498. doi:10.1175/BAMS-D-11-00094.1

Trigo RM, DaCamara CC (2000) Circulation weather types and their influence on the precipitation regime in Portugal. Int $\mathrm{J}$ Climatol 20(13):1559-1581

van Ulden AP, van Oldenborgh GJ (2006) Large-scale atmospheric circulation biases and changes in global climate model simulations and their importance for regional climate scenarios: a case study for West-Central Europe. Atmos Chem Phys 6:863-881

Vicente-Serrano SM, López-Moreno JI (2006) The influence of atmospheric circulation at different spatial scales on winter drought variability through a semi-arid climatic gradient in northeast Spain. Int J Climatol 26:1427-1453. doi:10.1002/ joc. 1387

Weigel AP, Liniger MA, Appenzeller C (2007) The discrete Brier and ranked probability skill scores. Mon Weather Rev 135:118-124

Wilby RL, Barnsley N, O'Hare G (1995) Rainfall variability associated with Lamb weather types: the case for incorporating weather fronts. Int J Climatol 15:1241-1252

Wilby RL, Charles SP, Zorita E, Timbal B, Whetton P, Mearns LO (2004) Guidelines for use of climate scenarios developed from statistical downscaling methods. Data distribution center of the intergovernmental panel on climate change

Wilhelm M et al (2016) North Sea region climate change assessment. Regional Climate Studies, pp 149-158

Yarnal B, Comrie AC, Frakes B, Brown DP (2001) Developments and prospects in synoptic climatology. Int J Climatol 21:1923-1950

Zhang X, Alexander LV, Hegerl GC, Klein-Tank A, Peterson TC, Trewin B, Zwiers FV (2011) Indices for monitoring changes in extremes based on daily temperature and precipitation data. Clim Change 2 851-870. doi:10.1002/wcc.147 